\title{
Distinct Brainstem and Forebrain Circuits Receiving Tracheal Sensory Neuron Inputs Revealed Using a Novel Conditional Anterograde Transsynaptic Viral Tracing System
}

\author{
Alice E. McGovern, ${ }^{1}$ Alexandria K. Driessen, ${ }^{1}$ David G. Simmons, ${ }^{1}$ Joseph Powell, ${ }^{2}$ @Nicholas Davis-Poynter, ${ }^{3}$ \\ (D) Michael J. Farrell, ${ }^{4}$ and Stuart B. Mazzone \\ ${ }^{1}$ School of Biomedical Sciences and ${ }^{2}$ Queensland Brain Institute, The University of Queensland, St. Lucia, Queensland, Australia 4072, ${ }^{3}$ Clinical Medical \\ Virology Centre/Queensland Children's Medical Research Centre, the University of Queensland and Sir Albert Sakzewski Virus Research Centre, Royal \\ Children's Hospital, Queensland, Australia 4029, and ${ }^{4}$ Department of Medical Imaging and Radiation Sciences, Monash University, Clayton, Victoria, \\ Australia 3800
}

Sensory nerves innervating the mucosa of the airways monitor the local environment for the presence of irritant stimuli and, when activated, provide input to the nucleus of the solitary tract (Sol) and paratrigeminal nucleus (Pa5) in the medulla to drive a variety of protective behaviors. Accompanying these behaviors are perceivable sensations that, particularly for stimuli in the proximal end of the airways, can be discrete and localizable. Airway sensations likely reflect the ascending airway sensory circuitry relayed via the Sol and Pa5, which terminates broadly throughout the CNS. However, the relative contribution of the Sol and Pa5 to these ascending pathways is not known. In the present study, we developed and characterized a novel conditional anterograde transneuronal viral tracing system based on the H129 strain of herpes simplex virus 1 and used this system in rats along with conventional neuroanatomical tracing with cholera toxin B to identify subcircuits in the brainstem and forebrain that are in receipt of relayed airway sensory inputs via the Sol and Pa5. We show that both the Pa5 and proximal airways disproportionately receive afferent terminals arising from the jugular (rather than nodose) vagal ganglia and the output of the Pa5 is predominately directed toward the ventrobasal thalamus. We propose the existence of a somatosensory-like pathway from the proximal airways involving jugular ganglia afferents, the Pa5, and the somatosensory thalamus and suggest that this pathway forms the anatomical framework for sensations arising from the proximal airway mucosa.

Key words: airway sensations; HSV-1 H129; neuroanatomical tracing; nucleus of the solitary tract; paratrigeminal; visceral sensation

\section{Introduction}

Irritations of the laryngotracheal mucosa evoke localizable unpleasant sensations dependent upon poorly defined circuits that involve vagal airway afferent input to subcortical and cortical brain regions involved in sensory processing (Mazzone et al., 2007; Mazzone et al., 2009; Davenport and Vovk, 2009; Mazzone et al., 2011; Farrell et al., 2012; McGovern et al., 2012a, 2012b, 2014). The proximal airway mucosa is principally innervated by afferents arising from the jugular vagal ganglia, in contrast to the distal airways and lung parenchyma, which are predominately

Received Dec. 17, 2014; revised March 12, 2015; accepted March 30, 2015.

Author contributions: D.G.S., N.D.-P., M.J.F., and S.B.M. designed research; A.E.M. and A.K.D. performed research; A.E.M., A.K.D., and J.P. analyzed data; A.E.M., A.K.D., D.G.S., N.D.-P., M.J.F., and S.B.M. wrote the paper.

This work was supported by the National Health and Medical Research Council of Australia (Grants 1042528, 1025589, and 1078943 to S.B.M. and M.J.F.). We thank Lynn Enquist and Halina Staniszewska Goraczniak (Princeton University, Princeton, NJ) for their generosity in supplying the original wild-type H129 strain of HSV-1.

The authors declare no competing financial interests.

Correspondence should be addressed to Stuart B. Mazzone, PhD, School of Biomedical Sciences, The University of Queensland, St Lucia, QLD Australia 4072.E-mail: s.mazzone@uq.edu.au.

DOI:10.1523/JNEUROSCI.5128-14.2015

Copyright $\odot 2015$ the authors $\quad 0270-6474 / 15 / 357041-15 \$ 15.00 / 0$ innervated by the nodose vagal ganglia (Kwong et al., 2008; Nassenstein et al., 2010; Lieu et al., 2011; McGovern et al., 2014). The jugular and nodose ganglia are embryologically distinct tissues derived from the neural crest (jugular) and epibranchial placodes (nodose) and can be considered as comprising the somatic and visceral sensory nervous system, respectively (Baker and Schlosser, 2005). Using recombinant neurotropic herpes viruses for transsynaptic circuit tracing in rats, we have shown that the trachea and lung in fact give rise to different ascending sensory circuits similarly differentiated by brain regions involved in somatosensory and viscerosensory processing (McGovern et al., 2012a, 2012b, 2014).

Within the brainstem, many airway vagal afferents terminate in the nucleus of the solitary tract (Sol), which is well known for its role in viscerosensory processing. However, the paratrigeminal nucleus ( $\mathrm{Pa} 5$ ), located in the dorsal lateral pole of the medullary spinal trigeminal tract, also receives primary afferent inputs from the airways (McGovern et al., 2012a, 2012b, 2014). This is consistent with a small but compelling body of literature showing that spinal, trigeminal, vagal, and glossopharyngeal afferent nerves terminate in this region (Ciriello et al., 1981; Panneton 
and Burton, 1981; Saxon and Hopkins, 2006). Interestingly, a larger population of $\mathrm{Pa} 5$ neurons receives tracheal afferent innervation compared with that from the lungs, suggesting that vagal inputs to the Pa5 skewed toward the somatic-like neurons of the jugular ganglia (McGovern et al., 2014). Although the Sol is well known for its role in coordinating respiratory and autonomic responses to a variety of afferent inputs, the role of the $\mathrm{Pa} 5$ in vagal afferent evoked responses is not clear. Several studies have shown an involvement of the $\mathrm{Pa} 5$ in the processing of painful stimuli (Arvidsson and Thomander, 1984; Marfurt and Turner, 1984; Cechetto et al., 1985; Bon et al., 1997, 1998; Suwanprathes et al., 2003; Alioto et al., 2008), suggesting that sensory input to the Pa5, rather than the Sol, may regulate sensations associated with proximal airway nociception, perhaps via distinct central circuitry. However, whether the airway-specific ascending circuits that arise from the $\mathrm{Pa} 5$ are different than those from the Sol is not known.

In the present study, we developed a novel conditional herpes virus neuroanatomical tracing system and used this, along with conventional tract tracing, to compare the ganglionic origin of vagal inputs to the Pa5 and the Sol and determine the airway afferentspecific subcortical projections arising from these two brainstem nuclei.

\section{Materials and Methods}

Experiments. All experiments involving animals were approved by The University of Queensland Institutional Animal Ethics Committee. Experiments were performed on adult male Sprague Dawley rats (150-250 $\mathrm{g}$ ), which were individually housed in a standard environment and given ad libitum access to water and food. All efforts were made to minimize the number of animals used and their discomfort.

Conventional neuroanatomical tracing. Dual tracing using fluorescently conjugated cholera toxin subunit B (CT-B) was used to label the vagal ganglia neurons terminating in the Sol and $\mathrm{Pa} 5$ retrogradely and to label terminal projections of Sol and $\mathrm{Pa} 5$ neurons throughout the neuraxis anterogradely. CT- $\mathrm{B}_{488}$ and CT- $\mathrm{B}_{594}$ (Invitrogen) were microinjected into the Sol and Pa5, respectively. Rats $(n=8)$ were anesthetized with isoflurane ( $2.5 \%$ in medical oxygen) via a nose cone and placed in a stereotaxic frame with the head angled at $45^{\circ}$. A midline incision was made though the animal's skin, posterior neck muscles, and dura mater to expose the medulla between the occipital bone and $\mathrm{C} 1$ vertebra. Using obex as a reference point ( $\sim 0.5 \mathrm{~mm}$ rostral to the calamus scriptorius), bilateral injections $(n=7)$ and a unilateral injection $(n=1)(50-100 \mathrm{nl}$ each injection; total volume per nucleus $=250-300 \mathrm{nl}$ ) of $2 \%$ CT-B were made into the Sol (from $0.3 \mathrm{~mm}$ caudal to $0.2 \mathrm{~mm}$ rostral to obex, $0-0.3$ $\mathrm{mm}$ lateral to the midline, and $0.5 \mathrm{~mm}$ below the medullary surface; $n=$ 4) and $\mathrm{Pa} 5$ (from $0 \mathrm{~mm}$ caudal to $1 \mathrm{~mm}$ rostral to obex, $2-3 \mathrm{~mm}$ lateral to the midline, and $0.5 \mathrm{~mm}$ below the medullary surface; $n=4$ ) using a calibrated glass micropipette (tip diameter $=40 \mu \mathrm{m}$ ) attached to a microprocessor pump (Pneumatic PicoPump; WPI). The glass micropipette was left in place for $5 \mathrm{~min}$ to limit the nonspecific spread of the tracer. Animals were allowed to recover for $7 \mathrm{~d}$.

To assess the proportion of jugular and nodose innervation to the proximal airways, in a separate cohort of animals $(n=4), 3 \mu \mathrm{l}$ of $2 \%$ CT- $\mathrm{B}_{488}$ was injected into the tracheal lumen (just caudal to the larynx). Vagal ganglia were removed from these animals $7 \mathrm{~d}$ after injection.

Conditional herpes viral tracing concept design and characterization. We designed a conditional herpes-based transneuronal tracing system to differentiate the airway-specific subcortical sensory circuits relayed via the Sol versus the Pa5. Our requirements for this system were that the neuronal tracing virus needed to be deliverable peripherally to the airways, but controllable in a manner to allow one central afferent relay projection pathway to be distinguished from all others. To achieve this, we built a replication competent Cre-inducible neurotropic herpes virus (HSV-1, strain $\mathrm{H} 129_{\text {floxed }}$ ) that undergoes Cre recombination to switch from expressing an EGFP to a tdTomato fluorescent reporter and used this in combination with adeno-associated viral vector (AAV) microinjection to drive Cre expression selectively within the Sol or Pa5. The H129 strain of HSV-1 can infect first-order neurons with terminals within the injection site by retrograde transport. However, transsynaptic spread of the H129 strain through complex neural circuits in the anterograde direction is significantly more efficient than in the retrograde direction (Barnett et al., 1995; McGovern et al., 2012a; Wojaczynski et al., 2014), albeit via mechanisms that are not well understood (for recent review, see Taylor and Enquist, 2015). Therefore, the rationale was that peripheral airway administration of $\mathrm{H}_{12} 9_{\text {floxed }}$ in animals expressing Cre in the Sol or Pa5 would allow the airway primary afferent neurons to be selectively infected retrogradely and then circuits arising from neurons in receipt of airway primary afferent inputs in each of these brainstem regions to be differentiated by following the progression of virally induced neuronal tdTomato expression (compared with that of the EGFP) in the brain (Fig. 1A,B).

A cloning vector was constructed in a single-step process by digesting a loxP-EGFP-HCMVpA-loxP insert (commercially synthesized onto a pN1 background) at HindIII sites and ligating into pH129 tdTomato (McGovern et al., 2014) between the HCMV promoter and the tdTomato cassette, resulting in the pH129 HCMV-loxP-EGFP-HCMVpA-loxPtdTomato-SV40pA. Correct ligation of the insert into the vector backbone was confirmed by restriction enzyme digestion, sequencing, and transfection into Vero cells (data not shown). Functionality of the construct was confirmed by cotransfecting pH129 HCMV-loxP-EGFP-HCMVpAloxP-tdTomato-SV40pA with a plasmid containing Cre-recombinase (pTurbo Cre, data not shown).

The H129 loxP-EGFP-loxP-tdTomato recombinant virus (i.e.,

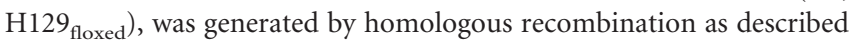
previously (McGovern et al., 2012b), which results in the expression cassette being incorporated into HSV-1 H129 between the UL26/26.5 and UL27 genes. Briefly, wild-type HSV-1 H129 DNA was cotransfected with pH129 HCMV-loxP-EGFP-HCMVpA-loxP-tdTomato-SV40pA into Vero cells using a calcium phosphate precipitation method (CellPhect; GE Healthcare) and infectious supernatant was serially diluted onto Vero cell monolayers. EGFP-expressing plaques were picked and plaque purified six times to remove wild-type HSV-1 H129 virus. Confirmation of correct insertion of the expression cassette into the H129 viral DNA was confirmed by sequencing (data not shown). Viral stocks were grown on Vero cells (McGovern et al., 2012b) and concentrated by ultracentrifugation $\left(140,000 \times g\right.$ for $3 \mathrm{~h}$ and $30 \mathrm{~min}$ at $4^{\circ} \mathrm{C}$, with the pellet resuspended in sterile PBS) to a final titer of $1 \times 10^{9} \mathrm{pfu} / \mathrm{ml}$. Infection of wild-type $3 \mathrm{~T} 3$ cells with the H129 floxed virus resulted in the exclusive expression of EGFP fluorescence, whereas infection of 3T3 Crerecombinase-expressing cells (generously provided by Philip Stevenson, Queensland, Australia) resulted in the exclusive expression of tdTomato fluorescence (Fig. 1C), indicating efficient and complete Cre-mediated recombination of virus. The growth of $\mathrm{H} 129_{\text {floxed }}$ determined by standard plaque assays on Vero cell monolayers was comparable to that of the wild-type $\mathrm{H} 129$ virus (peak titers $=3 \times 10^{7} \pm 7 \times 10^{1} \mathrm{pfu} / \mathrm{ml}$ and $2.7 \times$ $10^{7} \pm 8.5 \times 10^{1} \mathrm{pfu} / \mathrm{ml}$, respectively), indicating that the loxP-EGFPloxP tdTomato insert had not altered the replicative capacity of the recombinant virus. In the absence of Cre expression in the CNS, airway inoculation with $\mathrm{H} 129_{\text {floxed }}$ resulted in a time-dependent appearance of EGFP expression (but not tdTomato) throughout the neuraxis (Fig. 1D).

Targeted neuronal Cre expression in either the Sol $(n=13)$ or $\mathrm{Pa} 5$ $(n=14)$ of adult male Sprague Dawley rats $(100-150 \mathrm{~g})$ was achieved by bilateral microinjections of an AAV 2/2 HCMV EGFP-Cre expression vector (commercially obtained from The University of North Carolina Vector Core, Chapel Hill, NC) using the methods described above. Animals were allowed to recover for 2 weeks, after which they underwent a second surgery to inoculate the extrathoracic tracheal lumen ( 2 cartilage rings caudal to the larynx) with $15 \mu \mathrm{l}$ of $1 \times 10^{9} \mathrm{pfu} / \mathrm{ml}$ of the $\mathrm{H} 129_{\text {floxed }}$ (McGovern et al., 2012a, 2012b, 2014). We have shown previously that this procedure results in the restricted HSV-1 infection in the extrathoracic tracheal mucosa, with no spread into more proximal or rostral airways (McGovern et al., 2012a; McGovern et al., 2014), and this was confirmed in a limited number of animals in the present study. We have also previously reported that HSV-1 H129 appears in brainstem and subcortical forebrain regions 48-96 h (denoted "early" infection) and 96-120 h (denoted "mid" infection) postinoculation of the airways and subsequently in cortical brain regions in receipt of subcortical inputs at 120-168 h (denoted "late" infection) (McGovern et al., 2012a, 2012b, 


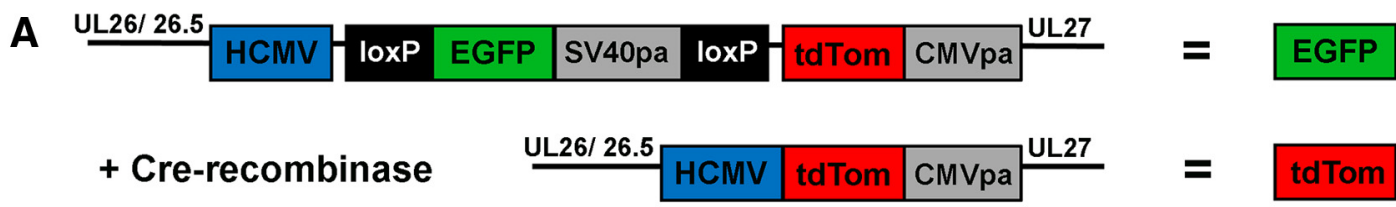

B

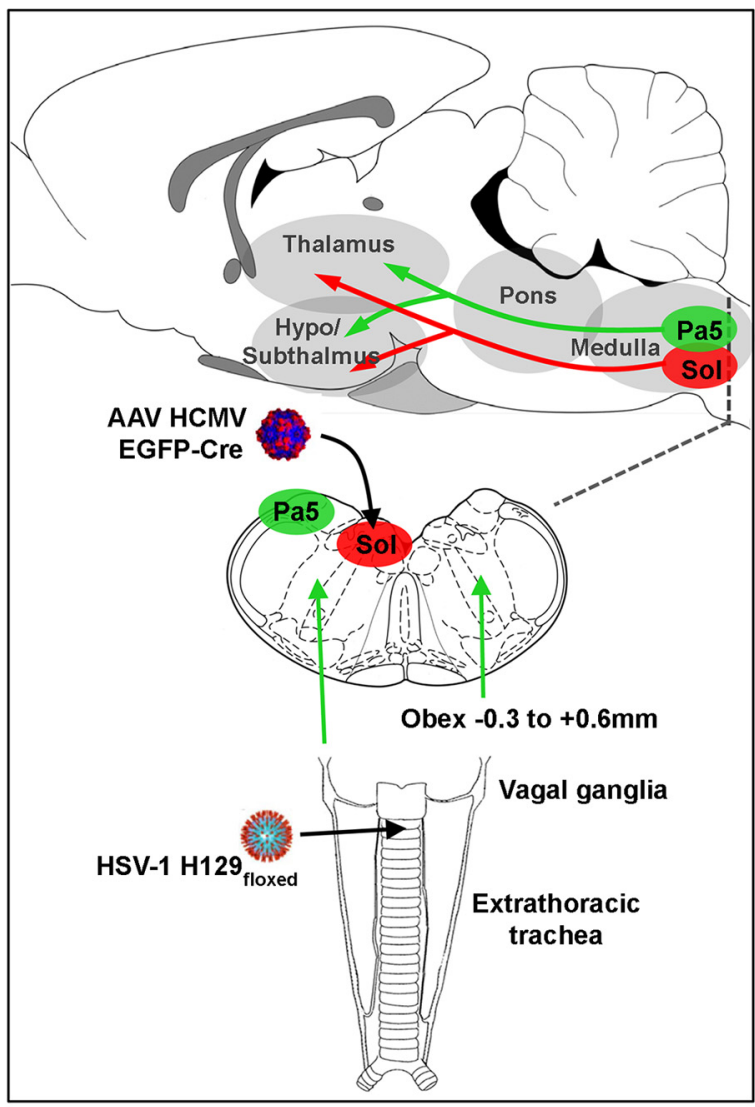

E
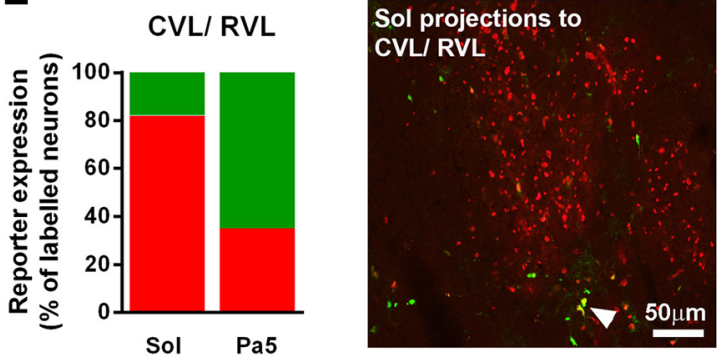

C
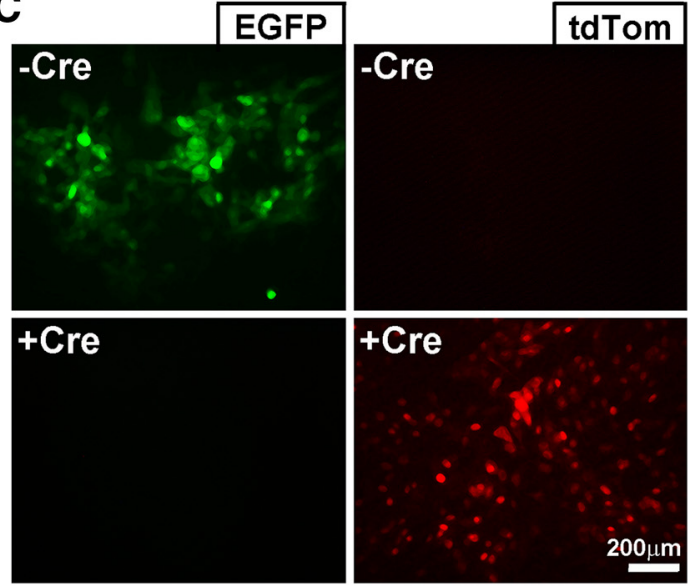

\section{H129floxed -Cre}

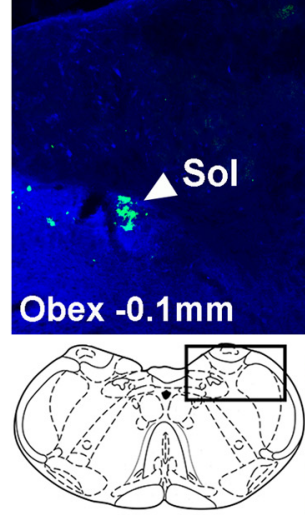

$\mathrm{Pa}$
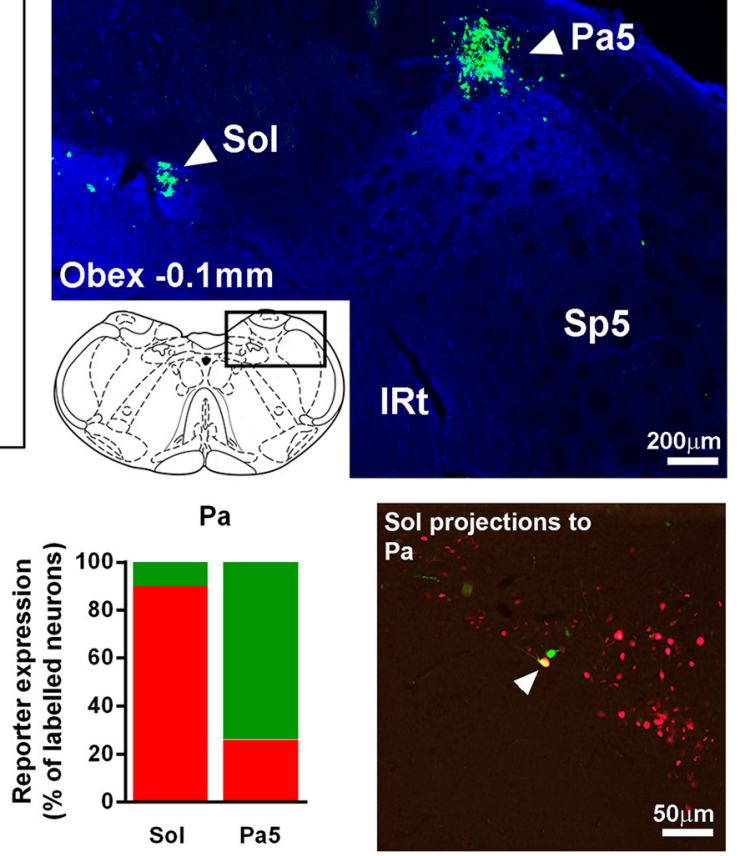

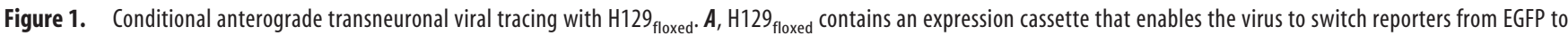
tdTomato in the presence of Cre-recombinase (Cre). $\boldsymbol{B}$, Expression of Cre in discrete populations of central neurons is achieved by microinjection of an AAV-Cre expression vector driven by a HCMV promoter. In the example shown, AAV-Cre is delivered to the Sol and not the Pa5. Two weeks after AAV-Cre injection, the trachea is inoculated with $\mathrm{H} 129_{\text {floxed }}$ and, as the virus moves from airway primary sensory neurons in the vagal ganglia to infect medullary relay nuclei, it is recombined in the Sol, but not the Pa5, resulting in viral-induced expression of tdTomato in Sol neurons as well as all synaptically connected neurons in the circuits arising from the Sol. Neural circuits arising from neurons that do not express (re (e.g., the Pa5) are also virally infected but display EGFP rather than tdTomato fluorescence. C, Infection of wild-type ( - Cre) 3 T3 cells with the H129 floxed virus results in the exclusive expression of EGFP (top), whereas infection of 3T3 Cre-expressing cells ( + Cre) results in the exclusive expression of tdTomato (bottom), indicating efficient and complete recombination of H129 floxed . , H129 floxed retains normal anterograde transsynaptic motility and, in the absence of Cre expression in the CNS, airway inoculation with H129 floxed results in a time-dependent appearance of EGFP expression (but not tdTomato) throughout the neuraxis (shown is EGFP expression in both the Sol and Pa5). $\boldsymbol{E}$, Graphs showing examples of the quantification of EGFP- (green bars) and tdTomato (red bars)-expressing cells in the caudal and rostral ventrolateral medulla (CVL/ RVL) and paraventricular nucleus (Pa). Notably, the ratio of EGFP to tdTomato at these central sites differs depending on whether AAV-Cre is delivered to the Sol or Pa5, indicative of the relative contribution of the Sol and Pa5 to the projections that terminate in the CVL/RVL and Pa. Photomicrographs represent examples of CVL/RVL and Pa neurons expressing tdTomato versus EGFP in animals transduced with AAV-Cre into the Sol. Arrowheads show dual infected neurons (yellow), which were rare. 
2014). In the present study, we focused on the brainstem and subcortical forebrain projections from the Sol and $\mathrm{Pa} 5$ and thus surveyed rats at early and middle time points. Therefore, animals were allowed to recover for a further 48-96 h (denoted "early" time point) or 96-120 h (denoted as "mid" time points). Animals receiving both the AAV injection into the brainstem and the tracheal injection of $\mathrm{H} 129_{\text {floxed }}$ contained on average $26.7 \pm 6.2$ EGFP-labeled cells and $0 \pm 0$ tdTomato-labeled cells in their vagal ganglia. All EGFP-labeled cells also immunostained positive for HSV-1 (data not shown). These data suggest that the AAV $2 / 2$ vector used to drive Cre expression in the Sol or Pa5 was devoid of any capacity to move retrogradely from the injection site, which would have confounded interpretation of subsequent experiments using this system to delineate the projection pattern of discrete brainstem regions.

Tissue harvest and immunostaining. After the designated survival time, animals were overdosed with sodium pentobarbital (100 mg/kg, i.p.) and transcardially perfused with $300 \mathrm{ml}$ of $5 \%$ sucrose in $0.1 \mathrm{M}$ PBS, pH 7.4, followed by $300 \mathrm{ml}$ of $4 \%$ paraformaldehyde in PBS, pH 7.4. Left and right vagal ganglia and brains were collected from all animals. Tissues were postfixed in $4 \%$ paraformaldehyde overnight at $4^{\circ} \mathrm{C}$ and then cryoprotected in $20 \%$ sucrose at $4^{\circ} \mathrm{C}$ and initially viewed as whole mounts to confirm the presence of traced cells. Frozen transverse sections $(16 \mu \mathrm{m})$ of ganglia from the medullary rootlets to the caudal end of the nodose ganglia were then made using a Hyrax C60 cryostat and thaw mounted in series onto gelatin-coated slides. Brains were frozen in OCT embedding compound and serially sectioned $(50 \mu \mathrm{m})$ from the olfactory bulbs to the spinomedullary junction and collected in series into $0.1 \mathrm{M}$ PBS. Every second section (i.e., at $100 \mu \mathrm{m}$ intervals) was mounted onto gelatincoated slides and screened for fluorescence (CT-B-positive terminals/ HSV-1 H129-infected neurons) using conventional fluorescence microscopy. When fluorescently labeled neurons were observed, the corresponding adjacent section was subsequently immunostained (free floating) using either rabbit anti-calbindin or mouse-parvalbumin antisera (1:500; Swant) to provide morphological detail for delineating the loci of neurons (McGovern et al., 2014) and these sections were used for quantitative analysis (see below). After the quantification of HSV-1infected cells, Cre expression in both the Sol and Pa5 was subsequently examined in brainstem sections from 22 animals (Sol, $n=11$, and Pa5, $n=11$ ). Briefly, sections were incubated at room temperature in the following: $0.03 \%$ hydrogen peroxide for $30 \mathrm{~min}$; mouse anti-Cre recombinase primary antisera (1:2000; Millipore) overnight; biotinylated antimouse antisera (Vector Laboratories) for $2 \mathrm{~h}$; avidin-biotin complex (ABC reagent; Vector Laboratories) for $1 \mathrm{~h}$; and developed in $0.05 \%$ diaminobenzidine (Sigma-Aldrich) in the presence of $0.015 \%$ hydrogen peroxide to produce a chromogen for visualization.

Data analysis and imaging. All tissues were examined for either the presence of CT-B or HSV-1 H129 using an Olympus BX51 microscope and representative images were captured with an Olympus DP72 camera. Digital images were imported into Adobe Photoshop CS4 (version 11.0) and optimized (minimally) for brightness, contrast, and size for preparation of representative photomicrographs. Retrogradely labeled neurons traced by CT-B or $\mathrm{H} 129_{\text {floxed }}$ in either jugular or nodose ganglia were quantified in every third section to limit recounting the same neurons and expressed as the mean \pm the SEM using the origin of the glossopharyngeal nerve to demarcate the junction between the two ganglia (Hayakawa et al., 2014). CT-B anterogradely labeled projections arising from either the Sol or Pa5 were analyzed using a modified label density protocol (Agster and Burwell, 2009). CT-B terminal density regions of interest were quantified in serial brain sections containing that region using a 5 -point scale $(0-4)$ at $400 \times$ magnification in which the approximate number of CT-B-positive fibers in the field of view were counted and scored as follows: $0=0$ fibers (no labeling), $1=1-25$ fibers (light labeling), $2=25-100$ fibers (mild labeling), $3=100-400$ fibers (moderate labeling), and $4=>400$ fibers (heavy labeling). All brain regions were assessed at $100 \mu \mathrm{m}$ increments and the score for each section of a brain region was summed to generate a cumulative label density representing the overall total score for a region of interest. The mean \pm SEM of this cumulative label density score was calculated where $n=$ the number of animals within each group. To test for statistical differences in the densities of neuronal terminal projections arising from the $\mathrm{Pa} 5$ and
Sol, we performed a mixed-effects logistic regression analysis. Each region displaying CT-B fiber labeling $(n=40)$ from each rat was fitted as a random effect to account for nongeneralized sample effects. Overall study-wide significance was evaluated using a Bonferroni correction to the nominal $\alpha$ threshold of 0.05 by the number of tested regions. In H129 floxed experiments, quantitative counts of the number of tdTomatoexpressing cells in each brain region of interest were performed at 100 $\mu \mathrm{m}$ intervals to limit the possibility of recounting the same cells in adjacent sections. Results are reported as the mean \pm SEM for $n=$ the number of animals per group; differences between injection sites were assessed using two-tailed unpaired Student's $t$ tests. In all instances, $p \leq$ 0.05 was considered significant. To determine the efficiency of recombination, infected cells expressing either EGFP or tdTomato were counted in every second section and expressed as a percentage of the total number of infected neurons surveyed across all animals in two representative brain regions, the caudal ventrolateral medulla and the paraventricular hypothalamic nucleus. For experiments assessing Cre expression in the brainstem, the total number of positively stained cells in the Sol and Pa5 were quantified in serial sections of each brainstem region and the mean data were tested for statistical differences between injection sites using two-tailed unpaired Student's $t$ test. A Pearson's correlation analysis was used to investigate the relationship between the number of Creexpressing brainstem cells and H129 tdTomato-expressing cells (recombined $\mathrm{H} 129$ virus) in brain regions of interest. In all instances, $p \leq 0.05$ was considered significant and brain regions were delineated and named according to the nomenclature defined in the Chemoarchitectonic Atlas of The Rat Brainstem and Forebrain (Paxinos et al., 1999a, 1999b) and the Rat Brain in Stereotaxic Coordinates, 4th edition (Paxinos and Watson, 1998).

\section{Results}

\section{Retrograde labeling of the vagal ganglia neurons projecting to the Sol and Pa5}

Sol and Pa5 microinjections appropriately encompassed regions where tracheal afferents terminate (cf. Figs. 1D, 2A), with the spread of injectate contained within nonoverlapping spheres of between 1.0 and $1.6 \mathrm{~mm}$ in diameter in all instances (Fig. 2A). Importantly, vagal sensory neurons retrogradely labeled with either $\mathrm{CT}-\mathrm{B}_{488}$ or CT- $\mathrm{B}_{594}$ were readily visible in whole-mount preparations of the vagal ganglia, albeit displaying a definitive rostrocaudal organization (Fig. 2C). Indeed, quantitative cell counts performed on histological sections revealed that the jugular ganglion contained significantly more neurons retrogradely labeled from the Pa5 compared with the Sol $(p=0.013)$, whereas the nodose ganglion contained significantly more neurons retrogradely labeled from the Sol compared with the Pa5 ( $p=0.002$; Fig. $\left.2 D, D^{\prime}\right)$. The interposed petrosal ganglion (data not shown) contained a larger number of neurons retrogradely labeled from the Sol than the Pa5, but this apparent difference was not significant (Sol, $20.3 \pm 9.2 ; \mathrm{Pa}$, $6.0 \pm$ 5.4). Consistent with previous studies (Lieu et al., 2011; McGovern et al., 2014), CT-B retrograde labeling of vagal afferents innervating the proximal tracheal mucosa revealed that, of a total of 209 neurons identified in four experiments, the majority (86.9 \pm $7.8 \%$ ) were contained within the jugular ganglia.

\section{Comparison of the brainstem projections arising from Sol and $\mathrm{Pa} 5$}

AAV microinjections resulted in the restricted expression of Cre to the Sol or Pa5. Although we noted a range of transduction efficiencies across different experiments, on average, the number of Cre-expressing cells identified in the two groups of animals was remarkably comparable and, importantly, we never saw Creexpressing cells in the $\mathrm{Pa} 5$ of animals receiving Sol injections or in the Sol when the Pa5 was injected (Fig. 3). In animals transduced to express Cre in either the Sol or the Pa5, the subsequent inoc- 

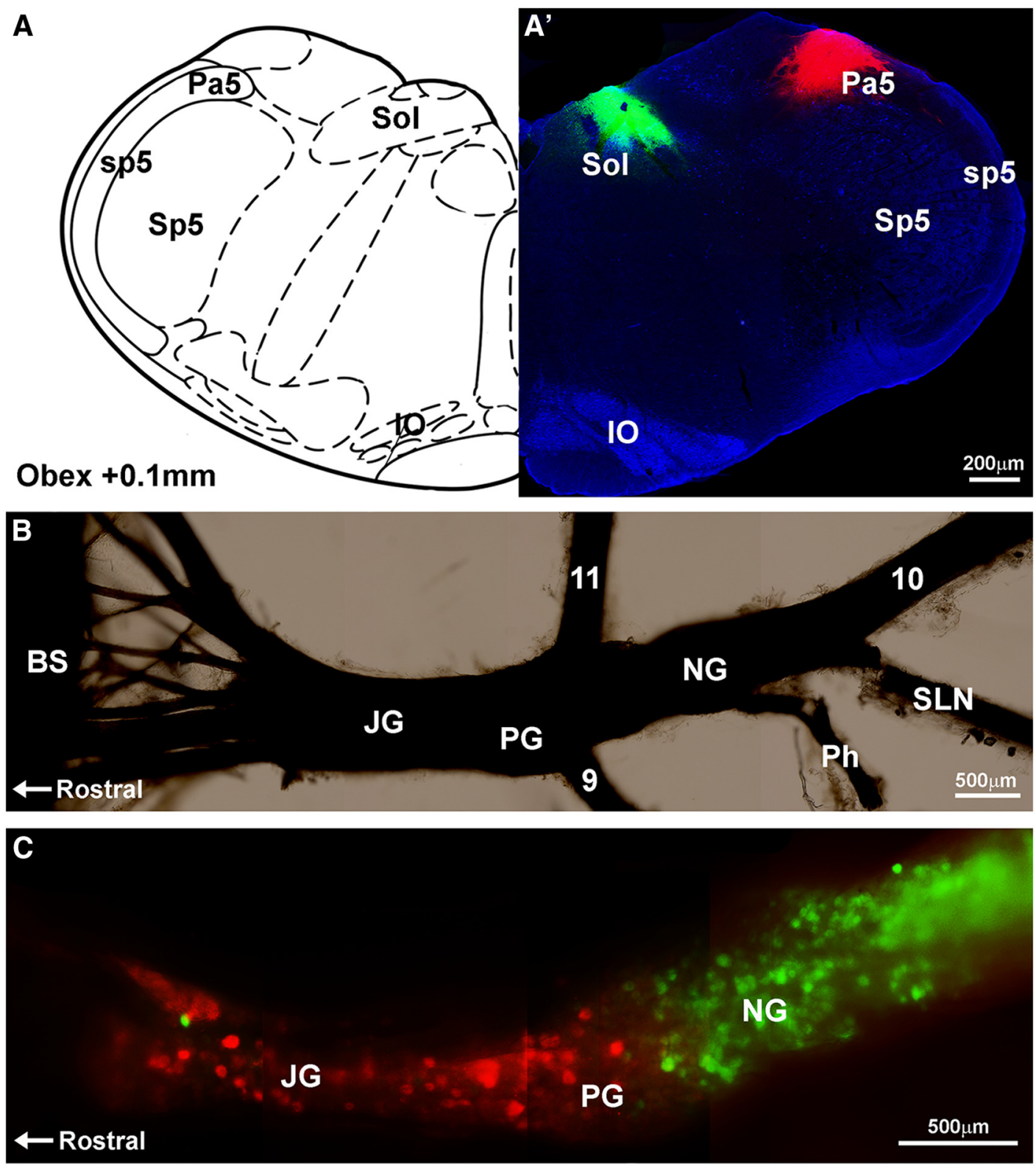

D Jugular

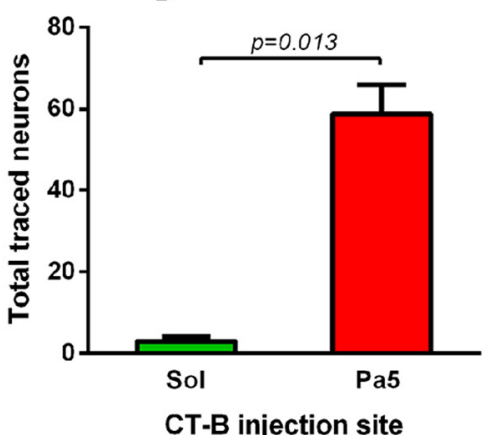

D' Nodose

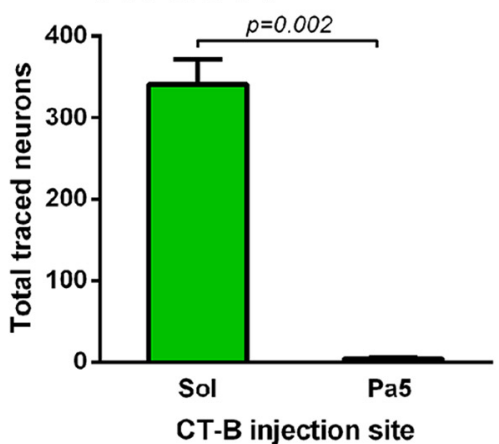

Figure 2. Differential terminations of jugular and nodose vagal ganglia neurons in the Pa5 and Sol. $\boldsymbol{A}$, Example photomicrograph and corresponding line drawing of a caudal brainstem section showing the Sol and Pa5 locations for microinjection of CT-B tracers conjugated with 488 (green) or 594 (red) fluorophores, respectively. $\boldsymbol{B}$, Bright-field photomicrograph of a whole-mount preparation of the rat vagal ganglia demonstrating the location of the jugular (JG) and nodose ganglia (NG) within the vagal sensory ganglia complex. $C$, Fluorescent photomicrograph of a whole-mount preparation of the rat vagal ganglia showing neuronal soma retrogradely labeled with CT-B from the Sol (green) and Pa5 (red). D, Quantitative cell counts performed on serial ganglia sections demonstrating that $\mathrm{Pa} 5$-projecting neurons reside in the jugular ganglia, whereas Sol projecting neurons are located within the nodose ganglia. Data are presented as the mean \pm SEM; $n=$ 7 dual tracing experiments. 9, Glossopharyngeal nerve; 10, vagus nerve; 11, accessory nerve; BS, brainstem; I0, inferior olives; PG, petrosal ganglia; Ph, pharyngeal branch; SLN, superior laryngeal nerve; Sp5, spinal trigeminal nucleus; sp5, spinal trigeminal tract. 
A

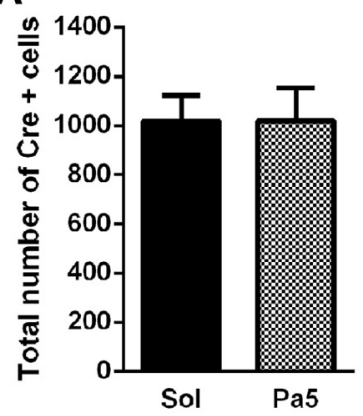

B Obex +0.6mm AAV-Cre Sol and H129
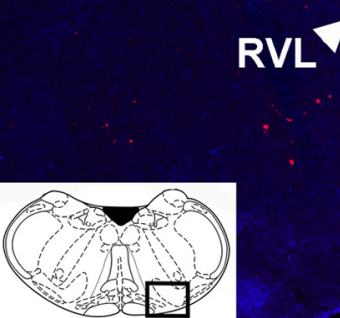

C

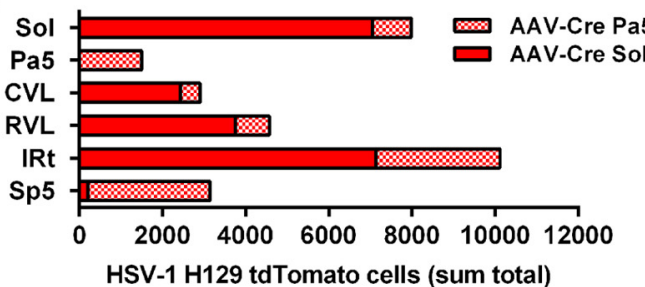

A'Obex $-0.1 \mathrm{~mm}$ AAV-Cre Sol

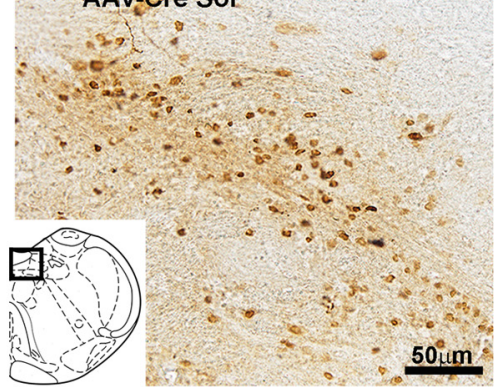

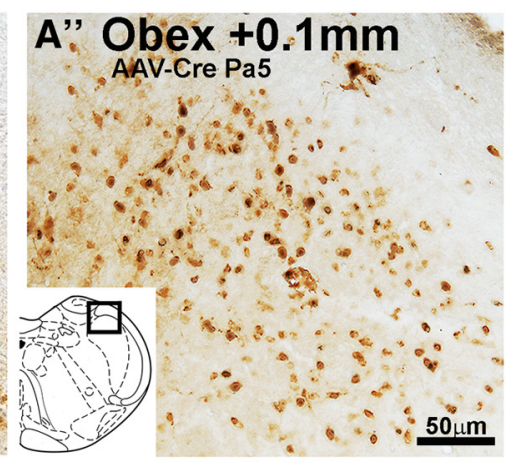

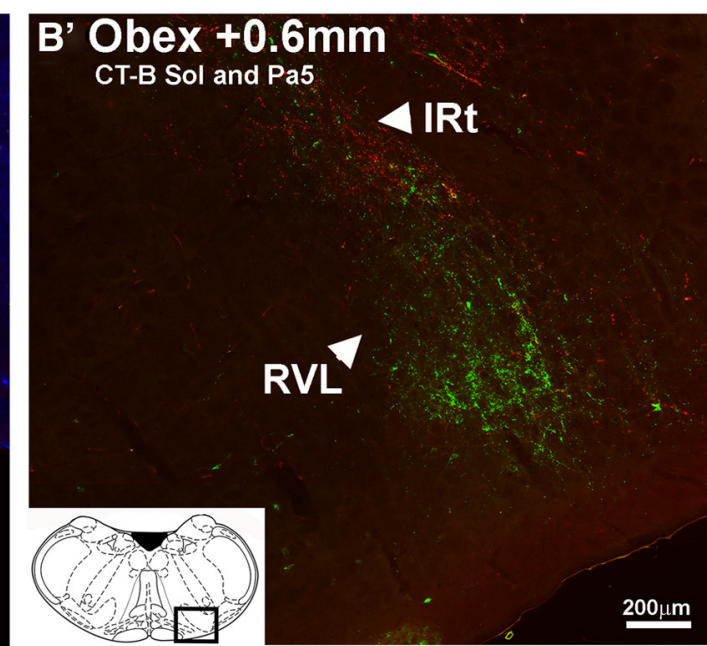

C'
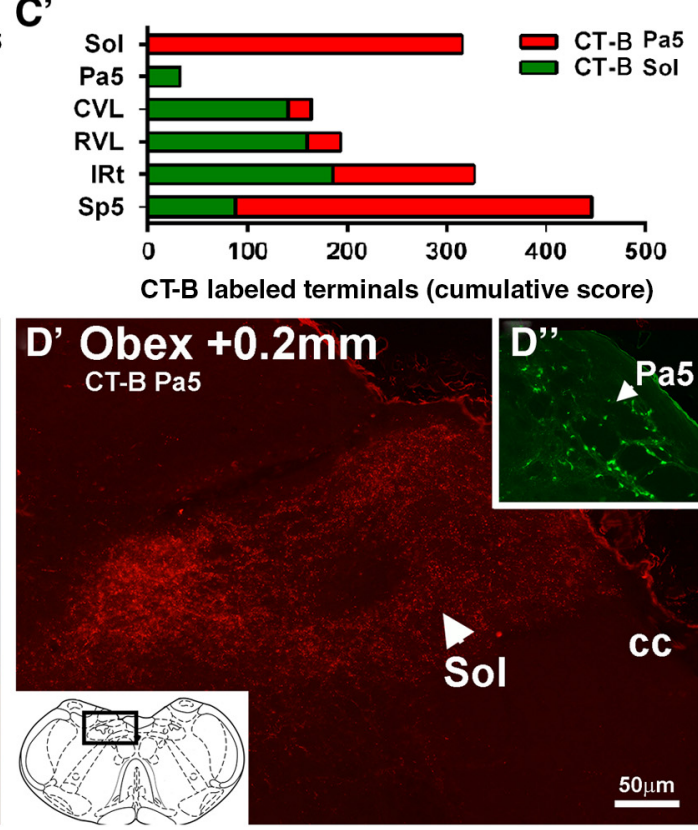

Figure 3. Differential medullary projections arising from the Sol and Pa5.A, Mean data showing quantification of the number of Cre-immunoreactive cells in serial brainstem sections of animals receiving microinjections of AAV-Creinto the Sol ( $n=11$ animals) versus $\mathrm{Pa} 5(n=11$ animals). Note the remarkably consistent number of Cre-expressing cells between the two groups. Representative photomicrographs show immunoperoxidase staining of (re-expressing cells in the Sol $\left(\boldsymbol{A}^{\prime}\right)$ and $\mathrm{Pa} 5\left(\boldsymbol{A}^{\prime \prime}\right)$. $\boldsymbol{B}$, Representative photomicrograph showing many tdTomato-expressing neurons in the rostral ventrolateral medulla (RVL) after tracheal inoculation with $\mathrm{H}_{12} 9_{\text {floxed }}$ in animals expressing Cre in the Sol. $\boldsymbol{B}^{\prime}$, Representative photomicrograph of a matching brainstem section from an animal with $\left(\mathrm{CT}-\mathrm{B}_{488}\right.$ and $\left(\mathrm{T}-\mathrm{B}_{594}\right.$ injected into the $\mathrm{Sol}$ and Pa5, respectively. Note the disproportionately greater density of direct monosynaptic projections from the Sol to the RVL. The graphs show the ratio of H129-infected tdTomato-expressing neurons in medullary nuclei of animals expressing (re in the Sol (solid red bars) versus Pa5 (shaded red bars; $\boldsymbol{C}$ ) and ( $\boldsymbol{C}^{\prime}$ ) the ratio of $\left(\mathrm{C}-\mathrm{B}_{488}\right.$ ( $\mathrm{green}$ bars, Sol injection) and $\mathrm{CT}^{-B_{594}}$ (red bars, Pa5 injection)-labeled terminals in the same medullary nuclei shown in $C$. In each instance, the bars represent the ratio of the summed data obtained from six animals (viral tracing,, and four animals (CT-B tracing, $\boldsymbol{C}^{\prime}$ ) and highlights differences in the relative contribution of inputs from the Sol and Pa5 to regions of interest. Mean data are presented in Tables 1 and 2. D, Representative photomicrograph of H129 virally infected tdTomato-expressing neurons in the Sol (arrows) in an animal transduced with Cre in the Pa5, indicative that some (albeit relatively few) airway afferent inputs to the Pa5 are relayed to the Sol. $\boldsymbol{D}^{\prime}$, Representative photomicrograph confirming extensive terminal fiber labeling in the Sol following (T-B ${ }_{594}$ injection into the Pa5. The inset ( $\left.\boldsymbol{D}^{\prime \prime}\right)$ shows retrogradely labeled neurons in the Pa5 after microinjection of $\left(T-B_{488}\right.$ into the Sol. Comparable reciprocal connectivity was not observed. cc, Central canal; CVL, caudal ventrolateral medulla; IRt, intermediate reticular formation; $4 V$, fourth ventricle. 
Table 1. Quantitative analysis of the number of HSV-1 H129 (tdTomato-positive) cells located in brain regions in receipt of airway afferent inputs via relay neurons in either the Sol or $\mathrm{Pa} 5$

\begin{tabular}{|c|c|c|c|c|}
\hline & \multicolumn{2}{|l|}{ Early $(n=10)$} & \multicolumn{2}{|l|}{$\operatorname{Mid}(n=17)$} \\
\hline & Sol $(n=6)$ & $\operatorname{Pa} 5(n=4)$ & Sol $(n=7)$ & $\operatorname{Pa} 5(n=10)$ \\
\hline \multicolumn{5}{|l|}{ Hindbrain } \\
\hline \multicolumn{5}{|l|}{ Medulla } \\
\hline Caudal ventrolateral (CVL) & $93.7 \pm 37.6(4)$ & $21.5 \pm 12.8(2)$ & $347.0 \pm 44.2(7)^{*}\left(p=1 \times 10^{-4}\right)$ & $49.1 \pm 22.1(5)$ \\
\hline Dorsomedial spinal trigeminal (DMSp5) & - & - & - & $73.5 \pm 22.4(6)^{*}(p=0.019)$ \\
\hline Gigantocellular reticular (DpGi, Gi, LpGi) & - & $21.3 \pm 15.9(2)$ & $154.7 \pm 51.0(5)$ & $63.9 \pm 26.0(5)$ \\
\hline Inferior olive (IOB, C, D) & $35.3 \pm 28.2(2)$ & $89.0 \pm 39.0(3)$ & $203.0 \pm 50.5(6)$ & $97.6 \pm 59.7(4)$ \\
\hline Intermediate reticular (IRt) & $234.6 \pm 138.7(5)$ & $59.5 \pm 26.4(3)$ & $1020.0 \pm 275.6(7)^{*}(p=0.01)$ & $332.3 \pm 85.2(9)$ \\
\hline Lateral reticular (LRt) & $53.0 \pm 39.5(2)$ & $30.2 \pm 12.3(3)$ & $288.7 \pm 76.2(7)^{*}(p=0.003)$ & $64.5 \pm 21.4(7)$ \\
\hline Medullary reticular formation (MdV) & $20.8 \pm 12.5(3)$ & - & $125.7 \pm 53.7(4)$ & $68.8 \pm 32.1(4)$ \\
\hline Sol & $498.0 \pm 78.5(6)^{*}(p=0.001)$ & - & $1007.3 \pm 272.9(6)^{*}(p=0.001)$ & $106.4 \pm 39.5(6)$ \\
\hline Paratrigeminal ( $\mathrm{Pa} 5)$ & - & $267.0 \pm 89.5(4)^{*}(p=0.01)$ & - & $273.3 \pm 76.2(8)^{*}(p=0.01)$ \\
\hline Paramedian reticular (PMn) & $41.3 \pm 26.1(3)$ & $42.5 \pm 42.5(1)$ & $165.4 \pm 55.2(5)$ & $80.0 \pm 27.5(6)$ \\
\hline Parvicellular recticular (PCRt) & - & - & $68.4 \pm 34.3(3)$ & $16.6 \pm 12.1(2)$ \\
\hline Pyramids (py) & $51.5 \pm 49.1(2)$ & $6.0 \pm 6.0(1)$ & $134.9 \pm 71.1(3)$ & $37.6 \pm 28.3(2)$ \\
\hline Rostral ventrolateral (RVL) & $198.8 \pm 93.9(4)$ & $10.5 \pm 10.5(1)$ & $536.6 \pm 108.9(7)^{*}(p=0.0003)$ & $83.6 \pm 40.4(5)$ \\
\hline Spinal trigeminal (Sp5) & $8.5 \pm 8.5(1)$ & $167.3 \pm 89.5(4)$ & $28.7 \pm 20.9(2)$ & $355.6 \pm 170.1(10)$ \\
\hline Spinal trigeminal tract (sp5) & - & $183.5 \pm 43.7(4)^{*}(p=0.002)$ & $36.3 \pm 36.3(1)$ & $145.5 \pm 90.6(5)$ \\
\hline \multicolumn{5}{|l|}{ Pons } \\
\hline Inferior cerebellar peduncle (icp) & - & $118.0 \pm 65.6(2)$ & $55.3 \pm 35.7(2)$ & $83.2 \pm 36.9(4)$ \\
\hline Kölliker-Fuse (KF) & $29.8 \pm 16.5(3)$ & - & $30.0 \pm 17.8(3)$ & $8.73 \pm 5.86(2)$ \\
\hline Locus coeruleus (LC) & $18.3 \pm 6.0(3)$ & $6.0 \pm 6.0(1)$ & $54.1 \pm 17.9(5)^{*}(p=0.03)$ & $15.2 \pm 5.8(5)$ \\
\hline Medial lemniscus (ml) & $59.7 \pm 44.6(2)$ & $42.3 \pm 42.3(1)$ & $133.6 \pm 40.1(5)$ & $140.0 \pm 42.7(8)$ \\
\hline \multicolumn{5}{|l|}{ Parabrachial } \\
\hline Medial (MPB) & - & $13.2 \pm 13.2(1)$ & $10.0 \pm 5.3(3)$ & $22.2 \pm 9.9(5)$ \\
\hline Lateral (LPB) & $32.2 \pm 17.8(3)$ & $1.8 \pm 1.8(1)$ & $134.4 \pm 36.8(7)^{*}(p=0.02)$ & $45.5 \pm 15.6(8)$ \\
\hline Principal sensory trigeminal (Pr5) & - & $114.0 \pm 114.0(1)$ & - & $199.0 \pm 88.8(8)$ \\
\hline Spinal trigeminal $(S p 5)$ & - & $25.5 \pm 25.5(1)$ & $9.7 \pm 9.7(1)$ & $253.1 \pm 82.4(9)^{*}(p=0.03)$ \\
\hline Spinal trigeminal tract (sp5) & - & $69.5 \pm 69.5(1)$ & - & $53.2 \pm 30.0(3)$ \\
\hline Superior cerebellar peduncle (scp) & - & $149.5 \pm 149.5(1)$ & $6.43 \pm 6.43(1)$ & $8.36 \pm 5.84(2)$ \\
\hline Trapezoid body (Tz) & - & - & $10.7 \pm 5.6(3)$ & $9.6 \pm 6.5(2)$ \\
\hline \multicolumn{5}{|l|}{ Midbrain } \\
\hline Deep mesencephalic (DpMe) & $53.17 \pm 23.4(4)$ & - & $95.4 \pm 32.8(6)$ & $27.0 \pm 19.1(3)$ \\
\hline Inferior colliculus (CIC, DCIC) & - & - & $45.9 \pm 34.7(2)$ & $26.1 \pm 26.1(1)$ \\
\hline Medial lemniscus (ml) & $95.8 \pm 54.6(3)$ & - & $213.4 \pm 68.2(6)$ & $152.8 \pm 29.0(9)$ \\
\hline Periaqueductual grey (PAG) & $2.0 \pm 2.0(1)$ & - & $13.4 \pm 5.2(4)$ & $15.0 \pm 6.6(5)$ \\
\hline \multicolumn{5}{|l|}{ Sub/hypothalamus and other } \\
\hline Caudate putamen (CPu) & - & - & $45.3 \pm 22.9(3)$ & $27.4 \pm 14.2(3)$ \\
\hline Central amygdaloid (CeA) & $18.7 \pm 18.7(1)$ & - & $63.1 \pm 29.6(4)^{*}(p=0.02)$ & $1.6 \pm 1.6(1)$ \\
\hline Globus pallidus (GP) & - & - & $16.4 \pm 8.2(3)$ & $5.1 \pm 5.1(1)$ \\
\hline Lateral hypothalamic area (LH) & $7.0 \pm 7.0(1)$ & - & $84.9 \pm 35.9(5)^{*}(p=0.02)$ & $11.6 \pm 6.5(3)$ \\
\hline Paraventricular hypothalamus $(\mathrm{Pa})$ & $29.17 \pm 17.64(3)$ & - & $139.2 \pm 56.1(5)^{*}(p=0.01)$ & $7.3 \pm 5.1(2)$ \\
\hline Subthalmic nucleus (SubT) & - & - & $60.4 \pm 35.6(3)$ & $4.9 \pm 4.9(1)$ \\
\hline Zona Incerta (ZI) & $148.3 \pm 79.3(4)$ & - & $278.6 \pm 72.5(7)^{*}(p=0.003)$ & $16.0 \pm 7.1(4)$ \\
\hline \multicolumn{5}{|l|}{ Thalamus } \\
\hline Medial lemniscus (ml) & - & - & $71.0 \pm 47.2(3)$ & $52.7 \pm 26.4(4)$ \\
\hline Mediodorsal thalamus (MD) & - & - & $6.4 \pm 6.4(1)$ & $1.1 \pm 1.1(1)$ \\
\hline Posterior thalamic group (Po) & - & - & $151.4 \pm 82.8(3)^{*}(p=0.035)$ & $3.3 \pm 3.3(1)$ \\
\hline Reticular thalamus (Rt) & - & - & $178.4 \pm 178.1(1)$ & $42.6 \pm 28.7(3)$ \\
\hline Submedius thalamus (Sub) & - & - & - & $175.4 \pm 65.0(6)^{*}(p=0.048)$ \\
\hline \multicolumn{5}{|l|}{ Ventral } \\
\hline Posterior parvicellular thalamus (VPPC) & - & - & - & - \\
\hline Posterolateral thalamus (VPL) & - & - & - & $417.0 \pm 132.2(10)^{*}(p=0.024)$ \\
\hline Posteromedial thalamus (VPM) & - & - & $321.4 \pm 215.8(3)$ & $257.4 \pm 116.4(7)$ \\
\hline Lateral thalamus (VL) & - & - & - & - \\
\hline Medial thalamus (VM) & - & - & $92.1 \pm 51.1(3)$ & $54.7 \pm 37.0(4)$ \\
\hline
\end{tabular}

The time points early and mid refer to the time points surveyed after viral inoculation (see Materials and Methods for details). Data represents the mean \pm SEM total number of tdTomato-expressing neurons counted for each brain region listed. Dashes denote that no tdTomato-expressing cells were seen in the region of interest in any of the animals (i.e., $0 \pm 0$ ). Values in parentheses represent the number of animals in the group in which the region of interest was infected (tdTomato expression). *Significant difference between regions receiving projections from either the Sol or Pa5 as determined by a Student's t test.

ulation of the trachea with $\mathrm{H} 129_{\text {floxed }}$ virus resulted in efficient time-dependent Cre-mediated $\mathrm{H} 129_{\text {floxed }}$ recombination and thus the appearance of tdTomato expression in upstream infected neurons throughout the brain (Table 1). Interestingly, the total number of tdTomato-expressing cells in the entire brain significantly correlated with the number of Cre-expressing cells identified within the Sol $\left(r^{2}=0.53 ; p=0.012 ; n=11\right)$ or $\operatorname{Pa} 5\left(r^{2}=0.65 ; p=0.003 ; n=\right.$ 11 ), indicative of a relationship between Cre expression and success- 
ful H129 $9_{\text {floxed }}$ recombination. However, the lack of a systematic difference between Cre expression in the two groups (Fig. 3) argues against this as confounding issue for the interpretation of group regional differences in tdTomato expression.

Within the medulla, tdTomato-expressing neurons were evident in varying numbers in a broad range of nuclei appearing initially at the early time point and becoming more expansive by the middle time point (Table 1). Although many medullary regions contained approximately equal numbers of tdTomatoexpressing neurons regardless of whether Cre was expressed in the Sol or Pa5 (Table 1), several regions were notable for having a clearly different ratio of tdTomato-expressing cells when Cre was transduced in the Sol versus the Pa5 (Fig. 3, Table 1). For example, the caudal and rostral ventrolateral medulla and intermediate reticular formation expressed more tdTomato cells when Cre was present in the Sol compared with the Pa5, whereas the spinal trigeminal complex in the medulla displayed more tdTomato cells when Cre was present in the Pa5 compared with the Sol (Fig. 3). This is indicative of the Sol and Pa5 differentially contributing the relayed airway sensory inputs to these brainstem regions. Consistent with this, anterograde fiber tracing using CT-B microinjections into the Sol and $\mathrm{Pa} 5$ yielded comparable results because the density of the inputs to the caudal and rostral ventrolateral medulla (but not the intermediate reticular formation) was greater from the Sol, whereas CT-B injection into the $\mathrm{Pa} 5$ produced more labeling of fibers throughout the trigeminal complex (Fig. 3, Table 2). There were additional medullary regions identified with CT-B tracing that demonstrated unequal terminal projections arising from the Sol versus the Pa5 (Table 2); however, the density of airway-specific inputs (tdTomatoexpressing cells in viral tracing) was not different (Table 1).

It was interesting that, at the middle time point, a small number of tdTomato-expressing virally infected neurons were observed in the Sol in 6 of 10 animals transduced with Cre in the $\mathrm{Pa} 5$, indicating that the Sol receives a small amount of airway afferent input indirectly via projections from neurons in the $\mathrm{Pa} 5$ (Fig. 3C, Table 1). Indeed, CT-B injected into the Pa5 produced extensive terminal fiber labeling in the caudal Sol (Fig. $3 C^{\prime}$ ), whereas CT-B injected into the Sol retrogradely labeled neurons in the Pa5 (Fig. 3C', inset). Relatively few CT-B-labeled fibers were present in the $\mathrm{Pa} 5$ after injection into the Sol (Table 2) and no Pa5 neurons expressed tdTomato after Cre transduction in the Sol (Table 1), indicating an absence of comparable reciprocal connectivity.

Several pontine and midbrain nuclei displayed tdTomatoexpressing virally infected neurons after Cre transduction within the Sol or Pa5, including the parabrachial complex, locus ceruleus, pontine trigeminal complex, deep mesencephalic nucleus, and the periaqueductal gray (Table 1). Within the parabrachial complex, most of the infected cells were contained in the lateral subnucleus, although smaller populations of medial parabrachial and Kölliker-Fuse nucleus neurons were consistently infected (Fig. 4, Table 1). More tdTomato-expressing neurons were present in the parabrachial complex and locus ceruleus when Cre was transduced in the Sol compared with the $\mathrm{Pa} 5$, whereas tdTomato expression in the pontine trigeminal nucleus was largely dependent on Cre transduction in the Pa5 rather than the Sol (Fig. 4D). CT-B microinjections showed dense inputs from the medulla to the lateral and medial parabrachial nuclei, with many of the terminals labeled originating from both the Sol and $\mathrm{Pa} 5$ (albeit with some predominance of Sol terminals in the lateral nucleus and Pa5 terminals in the medial nucleus; Fig. 4, Table 2). Comparably fewer CT-B-labeled terminals were present in the Kölliker-Fuse nucleus and locus ceruleus, the majority of which were anterogradely labeled from the Sol rather than the Pa5. Consistent with the viral tracing, CT-B microinjection in the Pa5, rather than the Sol, produced heavy terminal labeling in the pontine trigeminal nuclei (Fig. 4D').

\section{Comparison of the subcortical forebrain projections arising from Sol and $\mathrm{Pa} 5$}

In hypothalamic regions, $\mathrm{H} 129_{\text {floxed }}$ viral tracing in animals with Cre transduction in the Sol resulted in tdTomato expression that was predominately confined to neurons of the lateral hypothalamic area and paraventricular nucleus and was largely absent when Cre was transduced in the Pa5 (Fig. 5, Table 1). Cre transduction in the Sol compared with $\mathrm{Pa} 5$ also resulted in more tdTomato-expressing neurons in the subthalamic nucleus, zona incerta, and central amygdala (Fig. 5, Table 1). Virally infected neurons first appeared at the early time point surveyed in many of these nuclei and substantially increased in number at the middle time point, suggestive of at least some direct (monosynaptic) inputs arising from the Sol. The exception to this was the subthalamic nucleus in which infected neurons first appeared at the mid time point, indicative of an indirect relay via an (unidentified) intermediate nucleus (Table 1). Consistent with this notion, CT-B injection into the Sol produced mild terminal fiber labeling in the lateral hypothalamic area, paraventricular nucleus, and central amygdala and heavy labeling in the zona incerta, but no labeling in the subthalamic nucleus (Table 2). CT-B-labeled terminals arising from $\mathrm{Pa} 5$ neurons were largely absent in all of these nuclei (Fig. 5, Table 2).

Evidence for $\mathrm{H} 129$ viral infection within the thalamus was not apparent until the middle time point surveyed. tdTomatoexpressing neurons in the posterior and reticular thalamic nuclei were predominately dependent upon Cre transduction in the Sol rather than the Pa5 (Fig. 6, Table 1). In contrast, tdTomatoexpressing neurons were only seen in the ventral posterolateral and submedius thalamus when Cre was transduced in the Pa5, whereas the ventral posteromedial thalamus received relatively equal projections from both the Sol and Pa5. Interestingly, although our CT-B tracing revealed a relatively dense direct projection of Sol neurons to the posterior thalamus (and, to a lesser extent, the reticular thalamus), there were no CT-B-labeled fibers in the ventral posteromedial nucleus after Sol CT-B microinjection. Indeed, many CT-B-labeled terminals were identified in the ventral posterolateral thalamus arising from the Sol (Fig. 6, Table 2). Similarly, CT-B microinjection into the $\mathrm{Pa} 5$ produced terminal fiber labeling in the ventral posteromedial nucleus, but failed to label any terminals in the ventral posterolateral nucleus (Fig. 6, Table 2). Relatively few direct projections from the Pa5 to the submedius thalamus were identified with CT-B tracing (Fig. 6).

\section{Discussion}

Mucosal sensory nerves in the airways monitor the local environment for the presence of inhaled or locally produced irritants and, when activated, provide input to the Sol and $\mathrm{Pa} 5$ to drive a variety of protective reflex and behavioral responses. Perceivable sensations accompany evoked responses and, in many patients with respiratory diseases aberrant airway sensations contribute significantly to disease-induced morbidity. However, the neurobiology of respiratory sensation is poorly understood. We show that the Sol and Pa5 are in receipt of fundamentally different vagal afferent inputs and, in turn, these nuclei contribute differentially to neural circuits responsible for processing airway sensory information. These data suggest that distinct ascending pathways governing airway sensations likely exist, perhaps playing differing roles in how information arising from the airways is processed at higher brain levels. 
Table 2. Quantitative analysis of the density of terminal projections from the Sol and Pa5 after dual anterograde tracing with fluorescently-conjugated cholera toxin beta subunit (CT-B)

\begin{tabular}{|c|c|c|c|c|}
\hline & \multicolumn{2}{|l|}{ Cumulative density score $(n=4)$} & \multicolumn{2}{|c|}{ Peak density location $(n=4)$} \\
\hline & Sol & $\mathrm{Pa} 5$ & Sol & $\mathrm{Pa} 5$ \\
\hline \multicolumn{5}{|l|}{ Hindbrain } \\
\hline \multicolumn{5}{|l|}{ Medulla } \\
\hline Caudal ventrolateral (CVL) & $35.0 \pm 2.04(4)^{*}\left(p=1.72 \times 10^{-22}\right)$ & $6.00 \pm 2.19(4)$ & $-13.6 \mathrm{~mm}(\mathrm{i})$ & $-13.7 \mathrm{~mm}$ (i) \\
\hline Dorsomedial spinal trigeminal (DMSp5) & $3.00 \pm 1.91(2)$ & $86.25 \pm 3.17(4)^{*}\left(p=2.71 \times 10^{-75}\right)$ & $-11.2 \mathrm{~mm}(\mathrm{i})$ & $-11.7 \mathrm{~mm}$ (i) \\
\hline Gigantocellular reticular (DpGi, Gi, LpGi) & $5.25 \pm 5.25(1)$ & - & $\mathrm{N} / \mathrm{Ai}$ & - \\
\hline Inferior olive (IOB, C, D) & $35.50 \pm 6.40(4)^{*}\left(p=6.51 \times 10^{-17}\right)$ & $6.50 \pm 4.24(2)$ & $-13.0 \mathrm{~mm}(\mathrm{~b})$ & $-12.6 \mathrm{~mm}(\mathrm{~b})$ \\
\hline Intermediate reticular (IRt) & $46.50 \pm 3.7(4)^{*}(p=0.0005)$ & $35.50 \pm 3.01(4)$ & $-13.3 \mathrm{~mm}(\mathrm{i})$ & $-13.1 \mathrm{~mm}$ (i) \\
\hline Lateral reticular (LRt) & $7.50 \pm 6.50(2)$ & - & $-13.7 \mathrm{~mm}(\mathrm{i})$ & - \\
\hline Medullary reticular formation (MdV) & $3.50 \pm 1.80(4)^{*}(p=0.04)$ & - & $\mathrm{N} / \mathrm{Ai}$ & - \\
\hline Sol & - & $79.00 \pm 6.15(4)$ & - & $-13.7 \mathrm{~mm}$ (i) \\
\hline Paratrigeminal (Pa5) & $8.00 \pm 1.15(4)$ & - & $-13.9 \mathrm{~mm}$ (i) & - \\
\hline Paramedian reticular (PMn) & $8.25 \pm 2.59(4)^{*}(p=0.001)$ & - & $-13.5 \mathrm{~mm}$ (i) & - \\
\hline Parvicellular recticular (PCRt) & $18.0 \pm 4.08(4)$ & $12.75 \pm 4.64(4)$ & $-13.6 \mathrm{~mm}$ (i) & $-13.6 \mathrm{~mm}$ (i) \\
\hline Pyramids (py) & - & - & - & - \\
\hline Rostral ventrolateral (RVL) & $40.0 \pm 2.61(4)^{*}\left(p=1.55 \times 10^{-17}\right)$ & $8.50 \pm 2.06(4)$ & $-12.9 \mathrm{~mm}$ (i) & $-12.6 \mathrm{~mm}$ (i) \\
\hline Spinal trigeminal (Sp5) & $22.0 \pm 8.13(4)$ & $89.50 \pm 2.62(4)^{*}\left(p=3.2 \times 10^{-12}\right)$ & $-12.6 \mathrm{~mm}$ (i) & $-11.5 \mathrm{~mm}$ (i) \\
\hline Spinal trigeminal tract (sp5) & $9.00 \pm 3.44(4)$ & $95.00 \pm 3.78(4)^{*}\left(p=1.89 \times 10^{-70}\right)$ & $-13.7 \mathrm{~mm}$ (i) & $-11.5 \mathrm{~mm}$ (i) \\
\hline \multicolumn{5}{|l|}{ Pons } \\
\hline Inferior cerebellar peduncle (icp) & - & - & - & - \\
\hline Kölliker-Fuse (KF) & $14.75 \pm 1.89(4)^{*}(p=0.003)$ & $7.50 \pm 0.65(4)$ & $-9.4 \mathrm{~mm}$ (i) & $-9.6 \mathrm{~mm}(\mathrm{i})$ \\
\hline Locus coeruleus (LC) & $8.50 \pm 1.44(4)^{*}(p=0.005)$ & $2.00 \pm 1.68(2)$ & $-10.7 \mathrm{~mm}$ (i) & $-10.5 \mathrm{~mm}(\mathrm{i})$ \\
\hline Medial lemniscus (ml) & - & - & - & - \\
\hline \multicolumn{5}{|l|}{ Parabrachial } \\
\hline Medial (MPB) & $18.00 \pm 1.83(4)$ & $43.25 \pm 2.14(4)^{*}\left(p=1.15 \times 10^{-8}\right)$ & $-9.9 \mathrm{~mm}(\mathrm{i})$ & $-9.9 \mathrm{~mm}(\mathrm{i})$ \\
\hline Lateral (LPB) & $40.75 \pm 1.38(4)^{*}(p=0.0002)$ & $25.50 \pm 1.55(4)$ & $-9.5 \mathrm{~mm}(\mathrm{i})$ & $-9.9 \mathrm{~mm}$ (i) \\
\hline Principal sensory trigeminal (Pr5) & - & $12.00 \pm 10.40(2)$ & - & $-10.4 \mathrm{~mm}(\mathrm{i})$ \\
\hline Spinal trigeminal (Sp5) & $2.75 \pm 1.80(3)$ & $64.00 \pm 8.69(4)^{*}\left(p=1.6 \times 10^{-10}\right)$ & $-12.5 \mathrm{~mm}(\mathrm{i})$ & $-12.5 \mathrm{~mm}$ (i) \\
\hline Spinal trigeminal tract (sp5) & $3.00 \pm 3.00(1)$ & $44.75 \pm 6.60(4)^{*}\left(p=1.1 \times 10^{-8}\right)$ & $\mathrm{N} / \mathrm{Ai}$ & $-12.2 \mathrm{~mm}(\mathrm{i})$ \\
\hline Superior cerebellar peduncle (scp) & - & - & - & - \\
\hline Trapezoid body (Tz) & - & - & - & - \\
\hline \multicolumn{5}{|l|}{ Midbrain } \\
\hline Deep mesencephalic (DpMe) & $6.75 \pm 3.61(3)$ & $4.50 \pm 3.34(2)$ & $-7.5 \mathrm{~mm}(\mathrm{i})$ & $-7.6 \mathrm{~mm}$ (i) \\
\hline Inferior colliculus (CIC, DCIC) & $25.25 \pm 3.47(4)^{*}(p=0.003)$ & $7.50 \pm 6.55(2)$ & $-7.9 \mathrm{~mm}(\mathrm{c})$ & $\mathrm{N} / \mathrm{A}(\mathrm{c})$ \\
\hline Medial lemniscus (ml) & - & - & — & - \\
\hline Periaqueductual grey (PAG) & $19.50 \pm 3.07(4)$ & $20.00 \pm 4.49(4)$ & $N / A(b)$ & $N / A(b)$ \\
\hline \multicolumn{5}{|l|}{ Sub/hypothalamus and other } \\
\hline Caudate putamen (CPu) & - & - & - & - \\
\hline Central amygdaloid (CeA) & $12.25 \pm 1.18(4)^{*}\left(p=1.49 \times 10^{-13}\right)$ & - & $\mathrm{N} / \mathrm{Ai}$ & - \\
\hline Globus pallidus (GP) & - & - & - & - \\
\hline Lateral hypothalamic area (LH) & $14.00 \pm 1.73(4)^{*}\left(p=2.83 \times 10^{-9}\right)$ & $1.25 \pm 0.75(2)$ & $-3.6 \mathrm{~mm}(\mathrm{~b})$ & $\mathrm{N} / \mathrm{A}(\mathrm{b})$ \\
\hline Paraventricular hypothalamus ( $\mathrm{Pa}$ ) & $13.50 \pm 1.19(4)^{*}\left(p=2.95 \times 10^{-12}\right)$ & $1.00 \pm 0.41(3)$ & $N / A(b)$ & $\mathrm{N} / \mathrm{A}(\mathrm{b})$ \\
\hline Subthalmic nucleus (SubT) & - & - & - & - \\
\hline Zona incerta (Zl) & $47.25 \pm 4.01(4)^{*}\left(p=2.57 \times 10^{-19}\right)$ & - & $-4.5 \mathrm{~mm}$ (i) & - \\
\hline \multicolumn{5}{|l|}{ Thalamus } \\
\hline Medial lemniscus (ml) & - & - & - & - \\
\hline Mediodorsal thalamus (MD) & - & - & - & - \\
\hline Posterior thalamic group (Po) & $46.75 \pm 1.44(4)^{*}\left(p=6.2 \times 10^{-30}\right)$ & $1.25 \pm 0.63(3)$ & $-4.2 \mathrm{~mm}(\mathrm{c})$ & $\mathrm{N} / \mathrm{A}(\mathrm{c})$ \\
\hline Reticular thalamus (Rt) & $10.00 \pm 2.16(4)^{*}\left(p=5.76 \times 10^{-5}\right)$ & - & $-4.0 \mathrm{~mm}(\mathrm{c})$ & - \\
\hline Submedius thalamus (Sub) & - & $4.00 \pm 0.00(4)^{*}\left(p=3.15 \times 10^{-5}\right)$ & - & $-2.7 \mathrm{~mm}(\mathrm{~b})$ \\
\hline \multicolumn{5}{|l|}{ Ventral } \\
\hline Posterior parvicellular thalamus (VPPC) & - & $2.00 \pm 1.15(2)$ & - & $-3.8 \mathrm{~mm}(\mathrm{c})$ \\
\hline Posterolateral thalamus (VPL) & $55.00 \pm 2.52(4)^{*}\left(p=4.46 \times 10^{-33}\right)$ & $1.00 \pm 1.00(1)$ & $-2.9 \mathrm{~mm}(\mathrm{c})$ & $N / A(c)$ \\
\hline Posteromedial thalamus (VPM) & - & $24.50 \pm 5.20(4)^{*}\left(p=1.02 \times 10^{-5}\right)$ & - & $-3.7 \mathrm{~mm}(\mathrm{c})$ \\
\hline Lateral thalamus (VL) & - & - & - & - \\
\hline Medial thalamus (VM) & $6.00 \pm 2.48(3)^{*}(p=0.01)$ & - & $N / A(c)$ & \\
\hline
\end{tabular}

CT-B488 and CT-B594 injected into the Sol and Pa5, respectively. All brain regions were assessed in serial sections; data represent the mean cumulative sum of the terminal fiber label density \pm SEM (i.e., the sum score across multiple brain sections) and the peak density location (i.e., the brain section with the highest score relative to bregma) for each brain region listed; dashes denote $0 \pm 0$. Numerical values in parentheses represent the number of animals in the group in which a region contained CT-B-positive fibers.

i, Predominantly ipsilateral fiber labeling; b, predominantly bilateral fiber labeling; c, predominantly contralateral fiber labeling; N/A, no peak labeling was evident.

*Significant difference between Sol and Pa 5 brain regions as determined by a Student's $t$ test.

\section{Segregation of jugular and nodose afferent pathways to brainstem and forebrain nuclei}

The trachea in rats, mice, and guinea pigs is predominately innervated by sensory neurons arising from the jugular ganglia, whereas the distal airways and lung parenchyma contain many more terminals arising from nodose neurons (present study; Kwong et al., 2008; Nassenstein et al., 2010; Lieu et al., 2011; McGovern et al., 2014). This may have functional implications because the jugular and nodose ganglia have distinct molecular phenotypes and functionality because of their different embryo- 

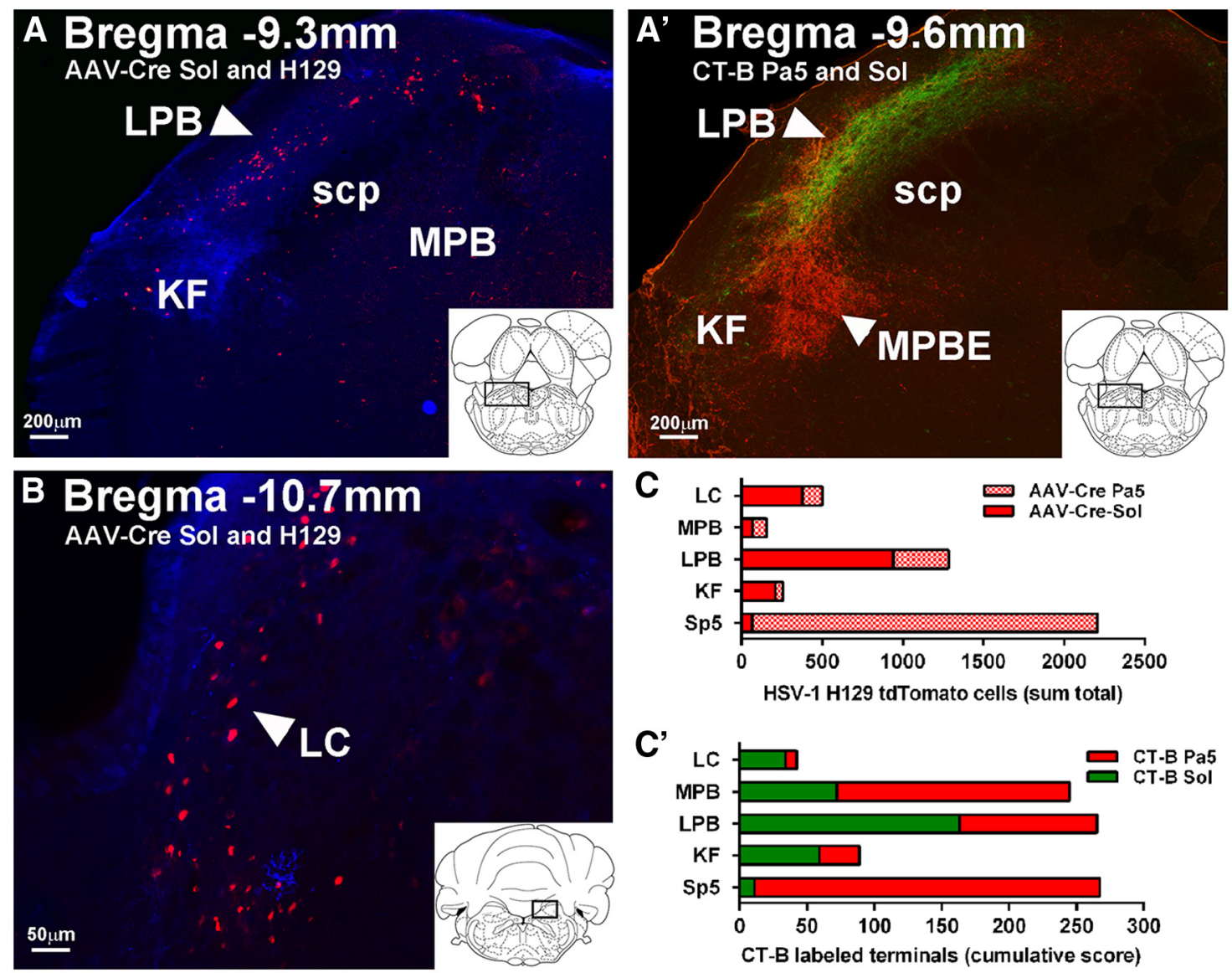

Figure 4. Differential pontine projections arising from the Sol and Pa5. A, Representative photomicrograph showing many tdTomato-expressing neurons in the parabrachial complex (particularly in the lateral parabrachial nucleus; LPB) after tracheal inoculation with $\mathrm{H}_{12} 9_{\text {floxed }}$ in animals expressing (re in the Sol. $A^{\prime}$, Representative photomicrograph of a matching brainstem section from an animal with $\left(T-B_{488}\right.$ and $\left(T-B_{594}\right.$ injected into the Sol and Pa5, respectively. Note the comparable distribution of direct monosynaptic projections from the Sol to the $L P B$ compared with the Pa5 projections that are predominately in the medial parabrachial externus nucleus (MPBE). $B$, Representative photomicrograph of tdTomato-expressing neurons in the locus ceruleus (LC) after tracheal inoculation with $\mathrm{H}_{12} 9_{\text {floxed }}$ in animals expressing Cre in the Sol. The graphs show the ratio of $\mathrm{H} 129$-infected tdTomato-expressing neurons in pontine nuclei of animals expressing Cre in the Sol (solid red bars) versus $\mathrm{Pa} 5$ (shaded red bars) $\left(\boldsymbol{C}\right.$ ) and the ratio of $\left(\mathrm{CT}-\mathrm{B}_{488}\right.$ - (green bars, Sol injection) and $\left(\mathrm{CT}-\mathrm{B}_{594}\right.$ (red bars, Pa5 injection)-labeled terminals $\left(\boldsymbol{C}^{\prime}\right)$ in the same pontine nuclei shown in $\boldsymbol{C}$. In each instance, the bars represent the ratio of the summed data obtained from six animals (viral tracing, $C$ ) and four animals (CT-B tracing, $C^{\prime}$ ) and highlights differences in the relative contribution of inputs from the Sol and Pa5 to regions of interest. Mean data are presented in Tables 1 and 2. KF, Kölliker-Fuse; scp, superior cerebellar peduncle.

logical origins (the neural crest and epibranchial placodes, respectively; D'amico-Martel and Noden, 1983; Undem et al., 2004; Kwong et al., 2008; D'autreaux et al., 2011; McGovern et al., 2014). Indeed, the neural crest cells of the jugular ganglia closely resemble somatic cells of the dorsal root ganglia, whereas the epibranchial placodes give rise to the visceral nervous system (D’amico-Martel and Noden, 1983; Nomaksteinsky et al., 2013), suggesting that a transition occurs from somatic to visceral sensory neural processing from the proximal to the distal airways (McGovern et al., 2014). Expression of distinct transcriptional elements including Runx1 and Phox2b delineate neural crest and placodal vagal neural development, respectively. Genetic deletion of Phox $2 \mathrm{~b}$ results in visceral sensory neurons acquiring a somatic phenotype and this coincides with a redirection of their central axon terminals from the Sol in favor of the spinal trigeminal nucleus (D'autreaux et al., 2011). Consistent with this, we found a stark dichotomy between the central termination sites of neurons in the jugular versus nodose ganglia, the former principally retrogradely labeled from the $\mathrm{Pa} 5$ and the latter from the Sol. Given that the majority of proximal airway afferents originate in the jugular ganglia, our findings suggest that afferent processing in the $\mathrm{Pa} 5$ may be critical for sensory responses from the proximal airways.
Although previous studies, including our own, show that vagal afferents terminate in both the Sol and trigeminal system (Ciriello et al., 1981; Panneton and Burton, 1981; McGovern et al., 2012a, 2012b, 2014), this is arguably underappreciated in studies of brainstem vagal afferent processing. Whereas a large body of literature has assessed vagal inputs to the Sol, only a handful of comparable studies have focused on the Pa5 (Balan Júnior et al., 2004; Saxon and Hopkins, 2006; Ma et al., 2007; Alioto et al., 2008; Caous et al., 2008). Furthermore, although conventional neuroanatomical tracing studies have delineated the generic neuronal projections arising from the Pa5 (Saxon and Hopkins, 1998; Caous et al., 2001; de Sousa Buck et al., 2001), there have been no studies of the central circuits that are specifically in receipt of vagal afferent inputs nor how these might differ to those of the Sol. Our results using conditional herpes viral tracing suggest that there is some commonality between brainstem and forebrain nuclei in receipt of airway sensory inputs via the Sol and Pa5. HSV-1 H129, when inoculated into the trachea, results in time-dependent infection within many CNS nuclei (McGovern et al., 2012a, 2012b, 2014), and the present data show that some of these regions receive approximately equal inputs from the Sol and Pa5. However, we also identified key differences (summarized in Fig. 7). Although there are significantly fewer 

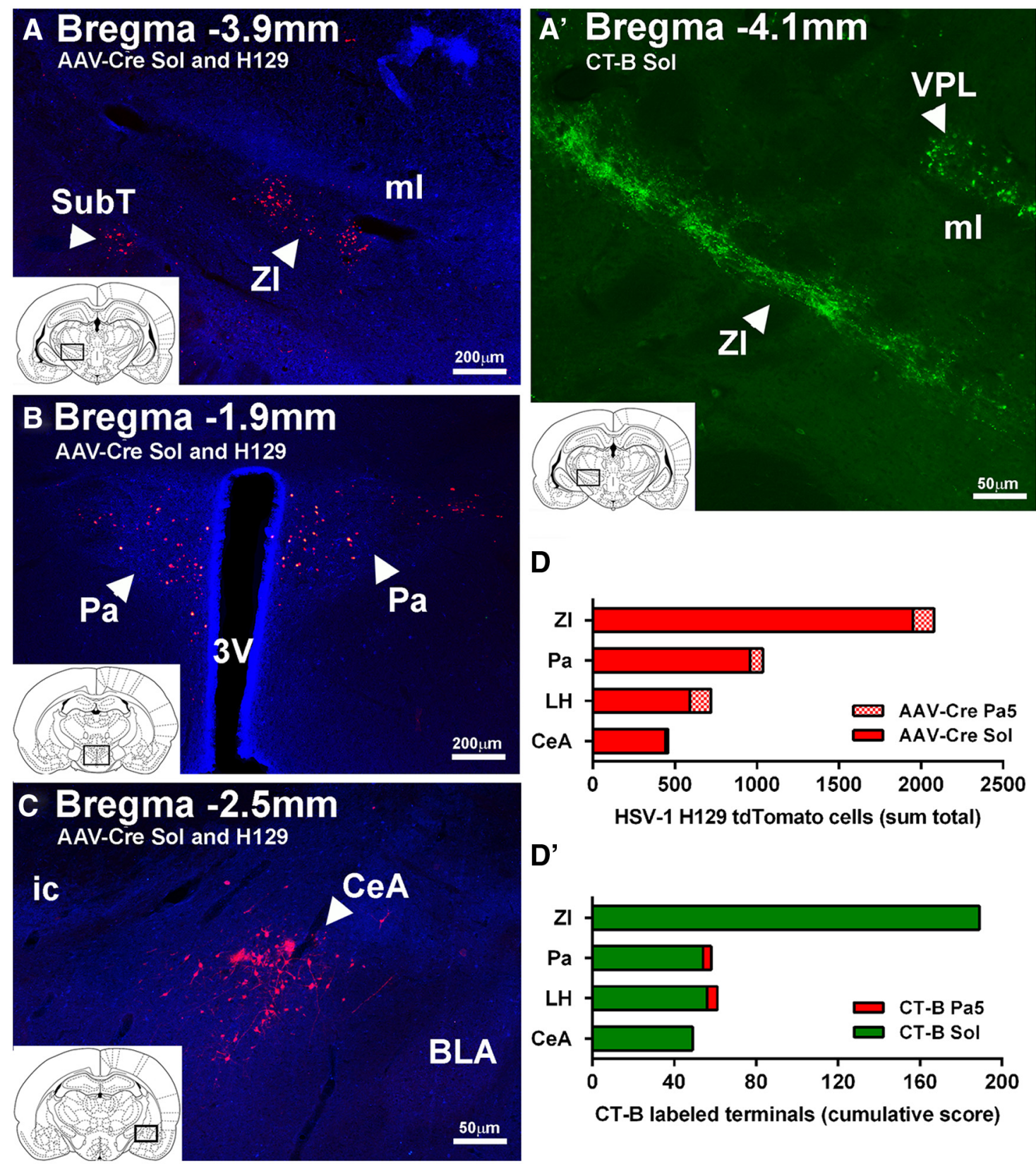

D'

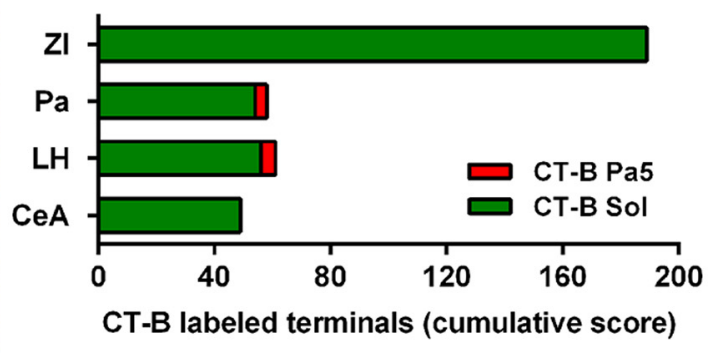

Figure 5. Differential hypothalamic, subthalamic, and amygdaloid projections arising from the Sol and Pa5. $A$, Representative photomicrograph showing many tdTomato-expressing neurons in the zona incerta (Zl) after tracheal inoculation with $\mathrm{H}_{129_{\text {floxed }}}$ in animals expressing Cre in the Sol. $\boldsymbol{A}^{\prime}$, Representative photomicrograph of a matching brainstem section from an animal with $\mathrm{CT}^{-\mathrm{B}_{488}}$ and $\mathrm{CT}_{-\mathrm{B}_{594}}$ injected into the Sol and Pa5, respectively. Note the comparable distribution of direct monosynaptic projections from the Sol to the Zl. $\boldsymbol{B}, \boldsymbol{C}$, Representative photomicrographs of tdTomato-expressing neurons in the central amygdala (CeA) and paraventricular nucleus of the hypothalamus ( $\mathrm{Pa}$ ) after tracheal inoculation with $\mathrm{H}_{12} \mathrm{f}_{\text {floxed }}$ in animals expressing $\mathrm{Cre}$ in the $\mathrm{Sol}$. The graphs show the ratio of $\mathrm{H} 129$ infected tdTomato-expressing neurons in hypothalamic, subthalamic, and amygdaloid nuclei of animals expressing Cre in the Sol (solid red bars) versus Pa5 (shaded red bars) (D) and the ratio of (T- $B_{488}$ (green bars, Sol injection) and CT- $B_{594}$ (red bars, Pa5 injection) labeled terminals in the same nuclei ( $\left.\boldsymbol{D}^{\prime}\right)$. In each instance, the bars represent the ratio of the summed data obtained from six animals (viral tracing, $\boldsymbol{D}$ ) and four animals ( $\left(T-B\right.$ tracing, $\boldsymbol{D}^{\prime}$ ) and highlights differences in the relative contribution of inputs from the Sol and Pa5 to regions of interest. Mean data are presented in Tables 1 and 2. BLA, Basolateral amygdala; ic, internal capsule; $\mathrm{ml}$, medial lemniscus; SubT, subthalamic nucleus; VPL, ventral posterolateral thalamus; 3V, third ventricle.

tracheal afferents originating from the nodose ganglia, nodose neurons (i.e., projections via the Sol) nevertheless make a substantial contribution to the central circuitry identified with our herpes viral tracing. Indeed, we recently reported that approximately the same number of Sol and Pa5 neurons become infected with HSV-1 H129 after tracheal inoculation, suggesting that individual nodose neurons have many more synaptic partners in the Sol than do jugular neurons terminating in the $\mathrm{Pa} 5$ (McGovern et al., 2014). Alternatively, a high degree of synaptic interconnectivity within the local circuitry of the Sol might serve to "amplify" the number of infected neurons that subsequently relay to higher-order processing sites. Regardless, tracheal sensory pathways relaying via the Sol to several brainstem and hypothalamic nuclei well known for their roles in autonomic control predominated over those from the Pa5 (Ciriello and Calaresu, 1980; Cechetto and Calaresu, 1985). In contrast, the $\mathrm{Pa} 5$ contributed substantially to the ascending inputs to the ventrobasal and submedius thalamus, regions known for their involvement in somatosensation (Zhang et al., 1995, 1998; Tang et al., 2009). 


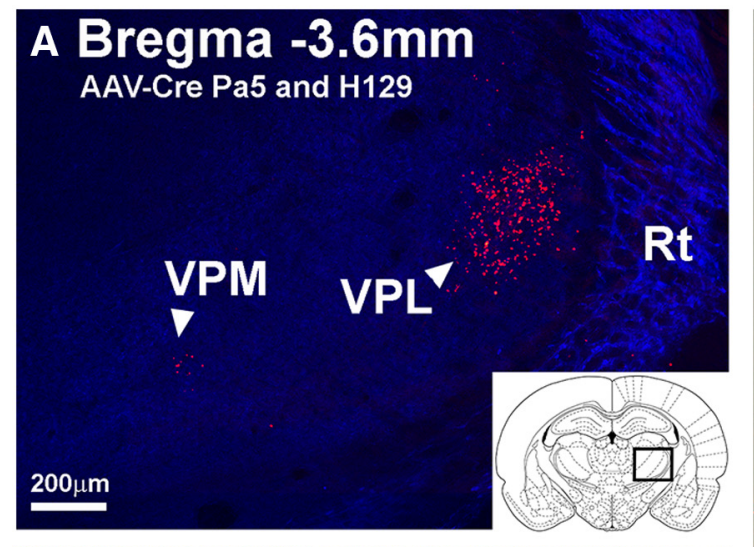

B Bregma -3.5mm AAV-Cre Sol and H129

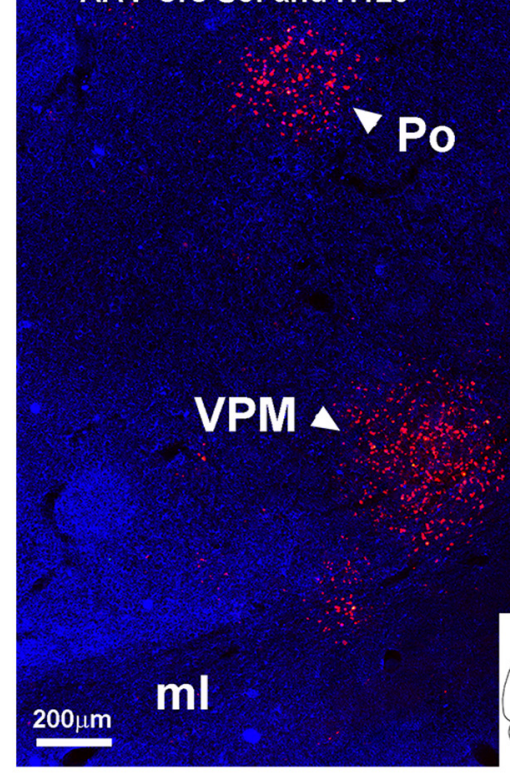

C Bregma -2.3mm AAV-Cre Pa5 and H129
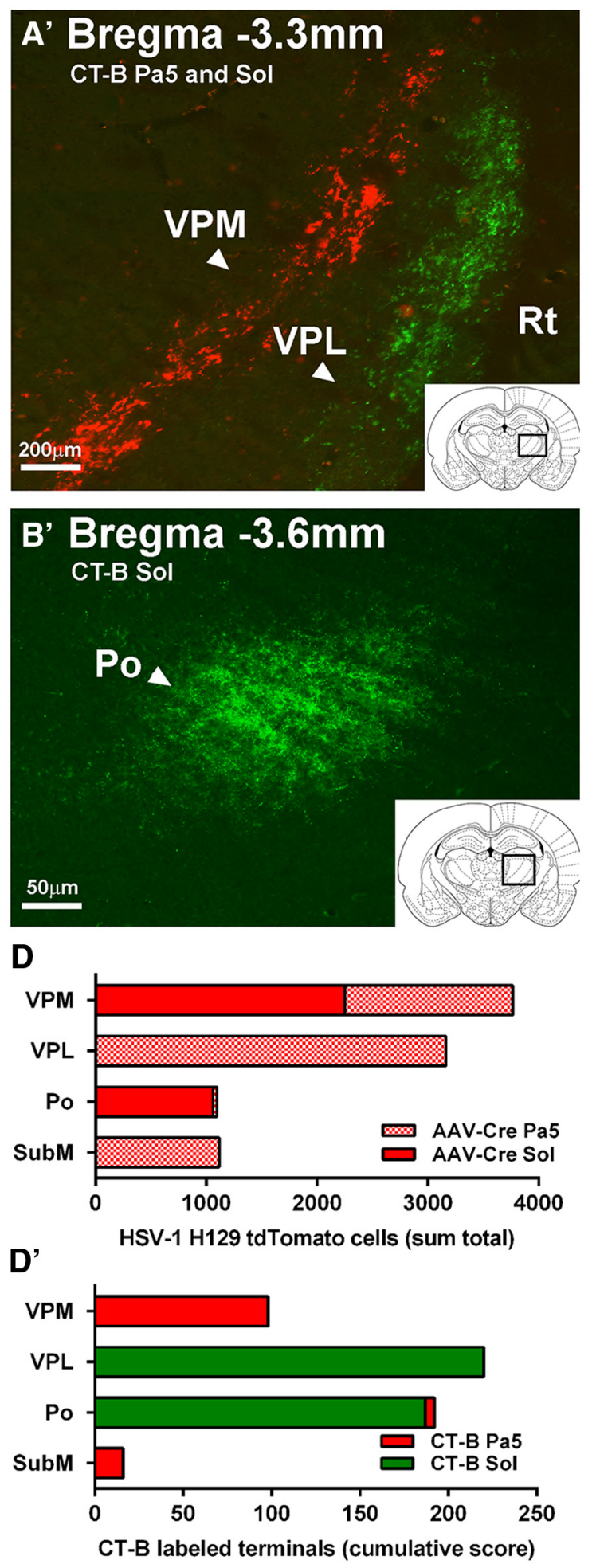

Figure 6. Differential thalamic projections arising from the Sol and Pa5. $\boldsymbol{A}$, Representative photomicrograph showing many tdTomato-expressing neurons in the ventral posterolateral nucleus (VPL) after tracheal inoculation with $\mathrm{H}_{129_{\text {floxed }}}$ in animals expressing (re in the Pa5. Note the comparably fewer tdTomato-expressing neurons in the ventral posteromedial nucleus (VPM) of the same animal. $\boldsymbol{A}^{\prime}$, Representative photomicrograph of a matching brainstem section from an animal with $\mathrm{CT}_{-B_{488}}$ and CT- ${ }_{594}$ injected into the Sol and Pa5, respectively. Note the dichotomy of the distribution of direct monosynaptic projections from the Sol to the VPL and the Pa5 to the VPM, suggesting that the VPL neurons infected with $\mathrm{H} 129_{\text {floxed }}$ virus in $\boldsymbol{A}$ must receive indirect inputs from the Pa5. B , Representative photomicrograph showing many tdTomato-expressing neurons in the VPM and posterior group ( $\mathrm{P0}$ ) after tracheal inoculation with $\mathrm{H} 129_{\text {floxed }}$ in animals expressing $\mathrm{Cre}$ in the Sol. $\boldsymbol{B}^{\prime}$, Representative photomicrograph of labeled terminals in the Po after microinjection of $C^{-}$B $_{488}$ into the Sol. $\boldsymbol{C}$, Representative photomicrograph of tdTomato-expressing neurons in the

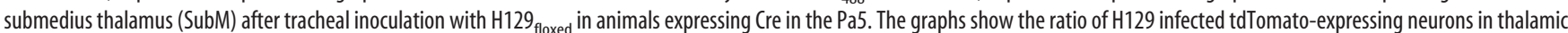
nuclei of animals expressing (re in the Sol (solid red bars) versus Pa5 (shaded red bars) ( $\boldsymbol{D}$ ) and the ratio of CT- B $_{488}$ - (green bars, Sol injection) and CT- $B_{594}$ (red bars, Pa5 injection)-labeled terminals $\left(\boldsymbol{D}^{\prime}\right)$ in the same nuclei shown in $\boldsymbol{C}$. In each instance, the bars represent the ratio of the summed data obtained from six animals (viral tracing, $\boldsymbol{D}$ ) and four animals (CT-B tracing, $\boldsymbol{D}^{\prime}$ ) and highlights differences in the relative contribution of inputs from the Sol and Pa5 to regions of interest. Note the relatively few direct monosynaptic inputs (CT-B-labeled terminals) into the SubM ( $\left.\boldsymbol{D}^{\prime}\right)$ from the Pa5. Mean data are presented in Tables 1 and 2. ml, Medial lemniscus; Rt, reticular nucleus; 3V, third ventricle. 


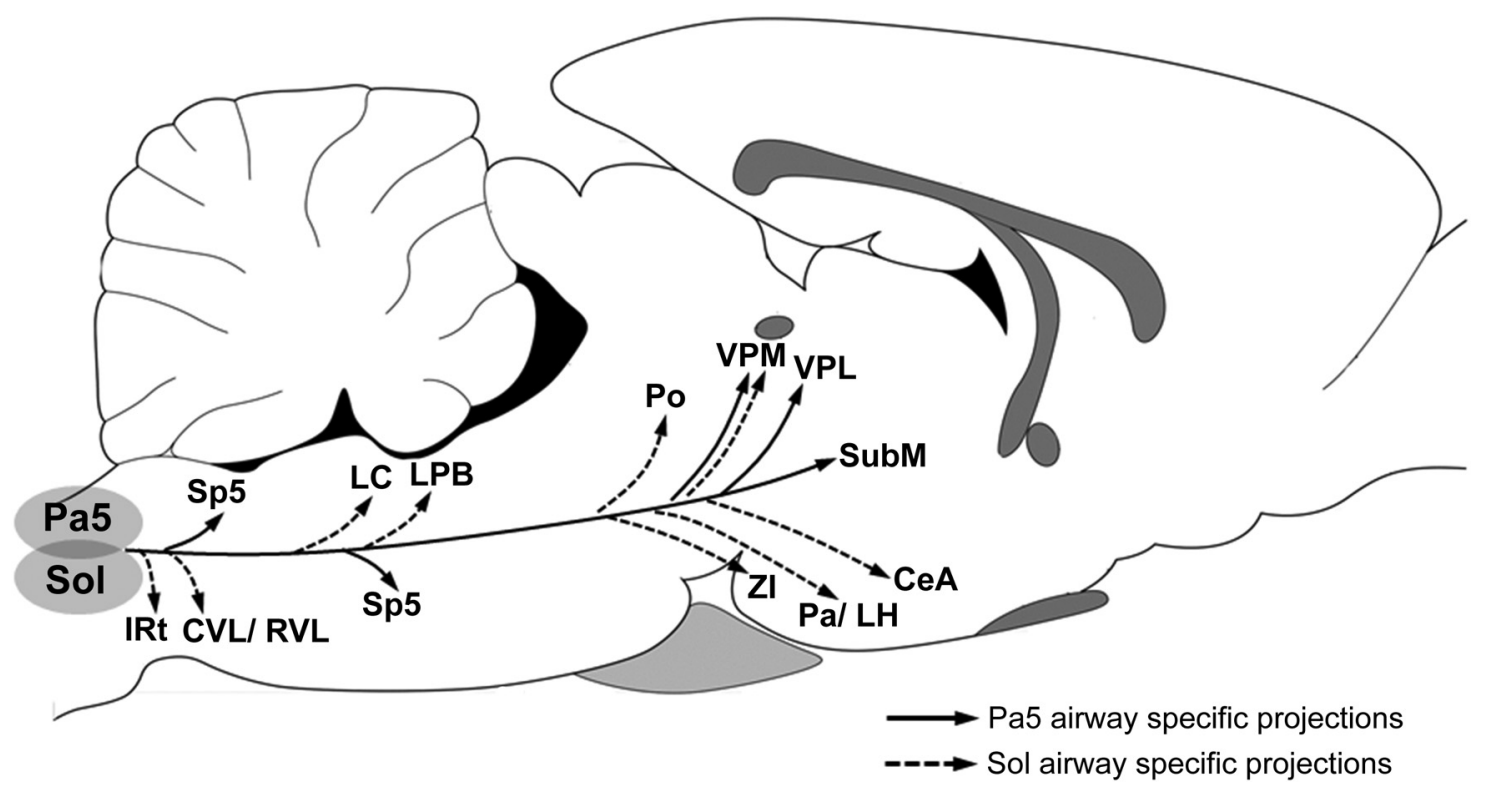

Figure 7. Sagittal schematic of the rat brain summarizing the proposed differences in the airway sensory circuitry relayed via Sol and Pa5. Dashed and solid lines show inputs to nuclei predominately arising from Sol and Pa5 neurons, respectively. The appearance of infected neurons in the caudal and rostral ventral lateral medulla (CVL/RVL), intermediate reticular nucleus (IRt), spinal trigeminal (Sp5), lateral parabrachial (LPB), locus ceruleus (LC), zona incerta (Zl), paraventricular hypothalamus (Pa), lateral hypothalamus (LH), and central amygdala (CeA) occurred at earlier time points (48-96 h), suggestive of direct monosynaptic inputs from the Sol or Pa5. In contrast, viral infection in posterior (Po), submedius (SubM), ventral posterolateral (VPL), and ventral posteromedial (VPM) of the thalamus did not occur until the middle time points ( $96-120 \mathrm{~h}$ ), indicative of a polysynaptic connection from the Sol or Pa5. Conventional tracing with CT-B further supports this notion.

H129 floxed conditional anterograde viral tracing: a useful tool for circuit analysis

We also report here the development and characterization of a novel viral tracing system for separating the polysynaptic connectivity of discrete populations of neurons. Although there have been conditional retrograde pseudorabies and rabies viral transsynaptic tracers developed (DeFalco et al., 2001; Campbell et al., 2007; Braz et al., 2009; Kobiler et al., 2010; Card et al., 2011a, 2011b; Sun et al., 2014), only one conditional anterograde HSV-1 H129 virus has been reported (Lo and Anderson, 2011) in which initial viral replication and reporter expression was dependent upon Cre recombination. Our virus is replication competent, so it can be used centrally or peripherally with the same efficacy as the parental virus, with the advantage of switching reporters during Cre-recombination. H129 $9_{\text {floxed }}$ successfully and specifically expressed EGFP in infected cells in the absence of Cre and underwent efficient recombination to express tdTomato in neurons containing Cre as well as those synaptically upstream. Employing this tool with local transduction of Cre has proven to be a powerful approach to dissect complex circuits anatomically. As an example of its utility, many lateral parabrachial neurons were infected after tracheal inoculation with $\mathrm{H}_{12} 9_{\text {floxed }}$ and these principally received their inputs via the Sol. However, conventional tracing with CT-B showed monosynaptic $\mathrm{Pa} 5$ projections to the lateral parabrachial nucleus, which presumably suggests that relatively few of these lateral parabrachial projecting $\mathrm{Pa} 5$ neurons receive inputs from airway afferents.

One disadvantage of the Cre transduction approach used is that the entire population of neurons within the Sol or Pa5 is unlikely to express Cre, potentially underestimating the projections arising from the nucleus of interest. Indeed, the significant correlation observed between Cre and tdTomato expression is consistent with this. Therefore, whereas the origin of tdTomatoexpressing neurons can be interpreted with confidence (i.e., they must have downstream connections with Cre-expressing neu- rons), it is difficult to interpret the origin of EGFP-positive neurons conclusively. Furthermore, it must be noted that the H129 virus is not completely devoid of retrograde motility and this could contribute to some of the labeling identified (Wojaczynski et al., 2014). However, retrograde movement is temporally delayed compared with anterograde movement and we have shown previously that there is negligible retrograde infection in well described airway autonomic (motor) circuits after tracheal injections (McGovern et al., 2012a). In the present study, many of the projections described with H129 tracing were also identified with anterograde CT-B tracing and much of this circuitry is widely known to be componentry of ascending sensory pathways.

\section{Implications and conclusions}

Many of the nuclei in receipt of airway sensory projections from both the Sol and Pa5 have well described roles in cardiorespiratory and visceral autonomic control. Populations of Sol and $\mathrm{Pa} 5$ neurons display activity that is locked to the cardiac cycle and activated baroreflexes (Yu and Lindsey, 2003; Balan Júnior et al., 2004; Caous et al., 2008; Sousa and Lindsey, 2009). This is consistent with the Sol and Pa5 having a mutual role in controlling autonomic responses, perhaps via overlapping projections onto autonomic nuclei described in the present study. Alternatively, the nonreciprocal projections of $\mathrm{Pa} 5$ neurons to the Sol described here and previously (Menétrey and Basbaum, 1987) may either help to coordinate autonomic processing between the two nuclei or, alternatively, $\mathrm{Pa} 5$ neurons may mediate autonomic responses indirectly via the Sol. This would offset the apparently fewer airway-specific outputs from the $\mathrm{Pa} 5$ to the ventrolateral medulla, paraventricular hypothalamus, and locus ceruleus (all intimately involved in autonomic control).

The Pa5 also plays a role in somatosensory processing. For example, $\mathrm{Pa} 5$ neurons respond to nociceptive sciatic nerve stimulation and orofacial pain (Arvidsson and Thomander, 1984; 
Marfurt and Turner, 1984; Cechetto et al., 1985; Alioto et al., 2008) and there is an upregulation of c-fos expression in the $\mathrm{Pa} 5$ after painful stimulation of the esophagus and urinary bladder (Bon et al., 1997, 1998; Suwanprathes et al., 2003). This involvement in nociception is consistent with the connectivity of the $\mathrm{Pa} 5$ with thalamic regions involved in somatosensory processing (present study; Zhang et al., 1995, 1998; Tang et al., 2009). Furthermore, the fact that tracheal afferents, presumably jugular in origin, provide substantive inputs to the somatosensory thalamus via the $\mathrm{Pa} 5$ suggests that this pathway may be particularly important for the subcortical processing of airway sensations. If this hypothesis is correct, then the present data may have important clinical implications because targeted modulation of trigemino-thalamocortical pathways could represent a novel approach to reducing aberrant sensations in airway disease.

\section{References}

Agster KL, Burwell RD (2009) Cortical efferents of the perirhinal, postrhinal, and entorhinal cortices of the rat. Hippocampus 19:1159-1186. CrossRef Medline

Alioto OE, Lindsey CJ, Koepp J, Caous CA (2008) Sensory sciatic nerve afferent inputs to the dorsal lateral medulla in the rat. Auton Neurosci 140:80-87. CrossRef Medline

Arvidsson J, Thomander L (1984) An HRP study of the central course of sensory intermediate and vagal fibers in peripheral facial nerve branches in the cat. J Comp Neurol 223:35-45. CrossRef Medline

Baker CV, Schlosser G (2005) The evolutionary origin of neural crest and placodes. J Exp Zool B Mol Dev Evol 304:269-273. Medline

Balan Júnior A, Caous CA, Yu YG, Lindsey CJ (2004) Barosensitive neurons in the rat tractus solitarius and paratrigeminal nucleus: a new model for medullary, cardiovascular reflex regulation. Can J Physiol Pharmacol 82: 474-484. CrossRef Medline

Barnett EM, Evans GD, Sun N, Perlman S, Cassell MD (1995) Anterograde tracing of trigeminal afferent pathways from the murine tooth pulp to cortex using herpes simplex virus type 1. J Neurosci 15:2972-2984. Medline

Bon K, Lantéri-Minet M, Menétrey D (1997) Involvement of the dorsal paratrigeminal nucleus in visceral pain-related phenomena. C R Acad Sci III 320:533-539. CrossRef Medline

Bon K, Lantéri-Minet M, Michiels JF, Menétrey D (1998) Cyclophosphamide cystitis as a model of visceral pain in rats: a c-fos and Krox-24 study at telencephalic levels, with a note on pituitary adenylate cyclase activating polypeptide (PACAP). Exp Brain Res 122:165-174. CrossRef Medline

Braz JM, Enquist LW, Basbaum AI (2009) Inputs to serotonergic neurons revealed by conditional viral transneuronal tracing. J Comp Neurol 514: 145-160. CrossRef Medline

Campbell RE, Herbison AE (2007) Definition of brainstem afferents to gonadotropin-releasing hormone neurons in the mouse using conditional viral tract tracing. Endocrinology 148:5884-5890. CrossRef Medline

Caous CA, de Sousa Buck H, Lindsey CJ (2001) Neuronal connections of the paratrigeminal nucleus: a topographic analysis of neurons projecting to bulbar, pontine and thalamic nuclei related to cardiovascular, respiratory and sensory functions. Auton Neurosci 94:14-24. CrossRef Medline

Caous CA, Koepp J, Couture R, Balan AC, Lindsey CJ (2008) The role of the paratrigeminal nucleus in the pressor response to sciatic nerve stimulation in the rat. Auton Neurosci 140:72-79. CrossRef Medline

Card JP, Kobiler O, McCambridge J, Ebdlahad S, Shan Z, Raizada MK, Sved AF, Enquist LW (2011a) Microdissection of neural networks by conditional reporter expression from a Brainbow herpesvirus. Proc Natl Acad Sci U S A 108:3377-3382. CrossRef Medline

Card JP, Kobiler O, Ludmir EB, Desai V, Sved AF, Enquist LW (2011b) A dual infection pseudorabies virus conditional reporter approach to identify projections to collateralized neurons in complex neural circuits. PLoS One 6:e21141. CrossRef Medline

Cechetto DF, Calaresu FR (1985) Central pathways relaying cardiovascular afferent information to amygdala. Am J Physiol 248:R38-R45. Medline

Cechetto DF, Standaert DG, Saper CB (1985) Spinal and trigeminal dorsal horn projections to the parabrachial nucleus in the rat. J Comp Neurol 240:153-160. CrossRef Medline
Ciriello J, Calaresu FR (1980) Monosynaptic pathway from cardiovascular neurons in the nucleus tractus solitarii to the paraventricular nucleus in the cat. Brain Res 193:529-533. CrossRef Medline

Ciriello J, Hrycyshyn AW, Calaresu FR (1981) Glossopharyngeal and vagal afferent projections to the brain stem of the cat: a horseradish peroxidase study. J Auton Nerv Syst 4:63-79. CrossRef Medline

D'Amico-Martel A, Noden DM (1983) Contributions of placodal and neural crest cells to avian cranial peripheral ganglia. Am J Anat 166:445-468. CrossRef Medline

D’Autréaux F, Coppola E, Hirsch MR, Birchmeier C, Brunet JF (2011) Homeoprotein Phox 2b commands a somatic-to-visceral switch in cranial sensory pathways. Proc Natl Acad Sci U S A 108:20018-20023. CrossRef Medline

Davenport PW, Vovk A (2009) Cortical and subcortical central neural pathways in respiratory sensations. Respir Physiol Neurobiol 167:72-86. Medline

DeFalco J, Tomishima M, Liu H, Zhao C, Cai X, Marth JD, Enquist L, Friedman JM (2001) Virus-assisted mapping of neural inputs to a feeding center in the hypothalamus. Science 291:2608-2613. CrossRef Medline

de Sousa Buck H, Caous CA, Lindsey CJ (2001) Projections of the paratrigeminal nucleus to the ambiguus, rostroventrolateral and lateral reticular nuclei, and the solitary tract. Auton Neurosci 87(2-3):187-200.

Farrell MJ, Cole LJ, Chiapoco D, Egan GF, Mazzone SB (2012) Neural correlates coding stimulus level and perception of capsaicin-evoked urge-tocough in humans. Neuroimage 61:1324-1335. CrossRef Medline

Hayakawa T, Kuwahara-Otani S, Maeda S, Tanaka K, Seki M (2014) Calcitonin gene-related peptide immunoreactive sensory neurons in the vagal and glossopharyngeal ganglia innervating the larynx of the rat. J Chem Neuroanat 55:18-23. CrossRef Medline

Kobiler O, Lipman Y, Therkelsen K, Daubechies I, Enquist LW (2010) Herpesviruses carrying a Brainbow cassette reveal replication and expression of limited numbers of incoming genomes. Nat Commun 1:146. CrossRef Medline

Kwong K, Kollarik M, Nassenstein C, Ru F, Undem BJ (2008) P2X2 receptors differentiate placodal vs. neural crest C-fiber phenotypes innervating guinea pig lungs and esophagus. Am J Physiol Lung Cell Mol Physiol 295:L858-L865. CrossRef Medline

Lieu T, Kollarik M, Myers AC, Undem BJ (2011) Neurotrophin and GDNF family ligand receptor expression in vagal sensory nerve subtypes innervating the adult guinea pig respiratory tract. Am J Physiol Lung Cell Mol Physiol 300:L790-L798. CrossRef Medline

Lo L, Anderson DJ (2011) A Cre-dependent, anterograde transsynaptic viral tracer for mapping output pathways of genetically marked neurons. Neuron 72:938-950. CrossRef Medline

Ma WL, Zhang WB, Xiong KH, Guo F (2007) Visceral and orofacial somatic afferent fiber terminals converge onto the same neuron in paratrigeminal nucleus: An electron microscopic study in rats. Auton Neurosci 131:45-49. CrossRef Medline

Marfurt CF, Turner DF (1984) The central projections of tooth pulp afferent neurons in the rat as determined by the transganglionic transport of horseradish peroxidase. J Comp Neurol 223:535-547. CrossRef Medline

Mazzone SB, McLennan L, McGovern AE, Egan GF, Farrell MJ (2007) Representation of capsaicin-evoked urge-to-cough in the human brain using functional magnetic resonance imaging. Am J Respir Crit Care Med 176: 327-332. CrossRef Medline

Mazzone SB, McGovern AE, Koo K, Farrell MJ (2009) Mapping supramedullary pathways involved in cough using functional brain imaging: comparison with pain. Pulm Pharmacol Ther 22:90-96. CrossRef Medline

Mazzone SB, Cole LJ, Ando A, Egan GF, Farrell MJ (2011) Investigation of the neural control of cough and cough suppression in humans using functional brain imaging. J Neurosci 31:2948-2958. CrossRef Medline

McGovern AE, Davis-Poynter N, Farrell MJ, Mazzone SB (2012a) Transneuronal tracing of airways-related sensory circuitry using Herpes Simplex Virus 1, strain H129. Neuroscience 207:148-166. CrossRef Medline

McGovern AE, Davis-Poynter N, Rakoczy J, Phipps S, Simmons DG, Mazzone SB (2012b) Anterograde neuronal circuit tracing using a genetically modified herpes simplex virus expressing EGFP. J Neurosci Methods 209:158-167. CrossRef Medline

McGovern AE, Davis-Poynter N, Yang SK, Simmons DG, Farrell MJ, Mazzone SB (2014) Evidence for multiple sensory circuits in the brain aris- 
ing from the respiratory system: an anterograde viral tract tracing study in rodents. Brain Struct Funct. In press.

Menétrey D, Basbaum AI (1987) Spinal and trigeminal projections to the nucleus of the solitary tract: a possible substrate for somatovisceral and viscerovisceral reflex activation. J Comp Neurol 255:439-450. CrossRef Medline

Nassenstein C, Taylor-Clark TE, Myers AC, Ru F, Nandigama R, Bettner W, Undem BJ (2010) Phenotypic distinctions between neural crest and placodal derived vagal C-fibres in mouse lungs. J Physiol 588:4769-4783. CrossRef Medline

Nomaksteinsky M, Kassabov S, Chettouh Z, Stoeklé HC, Bonnaud L, Fortin G, Kandel ER, Brunet JF (2013) Ancient origin of somatic and visceral neurons. BMC Biol 11:53. CrossRef Medline

Panneton WM, Burton H (1981) Corneal and periocular representation within the trigeminal sensory complex in the cat studied with transganglionic transport of horseradish peroxidase. J Comp Neurol 199:327-344. CrossRef Medline

Paxinos G, Watson C (1998) The rat brain in stereotaxic coordinates, Ed 4. San Diego: Academic.

Paxinos G, Carrive P, Wang H, Wang P-Y (1999a) Chemoarchitectonic atlas of the rat brainstem. San Diego: Academic.

Paxinos G, Kus L, Ashwell KWS, Watson C (1999b) Chemoarchitectonic atlas of the rat forebrain. San Diego: Academic.

Saxon DW, Hopkins DA (1998) Efferent and collateral organization of paratrigeminal nucleus projections: an anterograde and retrograde fluorescent tracer study in the rat. J Comp Neurol 402:93-110. Medline

Saxon DW, Hopkins DA (2006) Ultrastructure and synaptology of the paratrigeminal nucleus in the rat: primary pharyngeal and laryngeal afferent projections. Synapse 59:220-234. CrossRef Medline

Sousa LO, Lindsey CJ (2009) Cardiovascular and baroreceptor functions of the paratrigeminal nucleus for pressor effects in non-anaesthetized rats. Auton Neurosci 147:27-32. CrossRef Medline

Sun Y, Nguyen AQ, Nguyen JP, Le L, Saur D, Choi J, Callaway EM, Xu X (2014) Cell-type-specific circuit connectivity of hippocampal CA1 revealed through Cre-dependent rabies tracing. Cell Rep 7:269-280. CrossRef Medline

Suwanprathes P, Ngu M, Ing A, Hunt G, Seow F (2003) c-Fos immunoreactivity in the brain after esophageal acid stimulation. Am J Med 115:31S38S. Medline

Tang JS, Qu CL, Huo FQ (2009) The thalamic nucleus submedius and ventrolateral orbital cortex are involved in nociceptive modulation: a novel pain modulation pathway. Prog Neurobiol 89:383-389. CrossRef Medline

Taylor MP, Enquist LW (2015) Axonal spread of neuroinvasive viral infections. Trends Microbiol. In press.

Undem BJ, Chuaychoo B, Lee MG, Weinreich D, Myers AC, Kollarik M (2004) Subtypes of vagal afferent C-fibres in guinea-pig lungs. J Physiol 556:905-917. CrossRef Medline

Wojaczynski GJ, Engel EA, Steren KE, Enquist LW, Patrick Card J (2014) The neuroinvasive profiles of H129 (herpes simplex virus type 1) recombinants with putative anterograde-only transneuronal spread properties. Brain Struct Funct. In press.

Yu YG, Lindsey CJ (2003) Baroreceptor-sensitive neurons in the rat paratrigeminal nucleus. Auton Neurosci 105:25-34. CrossRef Medline

Zhang S, Tang JS, Yuan B, Jia H (1998) Inhibitory effects of glutamate-induced activation of thalamic nucleus submedius are mediated by ventrolateral orbital cortex and periaqueductal gray in rats. Eur J Pain 2:153-163. CrossRef Medline

Zhang YQ, Tang JS, Yuan B, Jia H (1995) Inhibitory effects of electrical stimulation of thalamic nucleus submedius area on the rat tail flick reflex. Brain Res 696:205-212. CrossRef Medline 